\title{
WestVirginiaUniversity。
}

Department of Economics

Working Paper Series

\section{Honest Abe or Doc Holliday? \\ Bluffing in Bargaining}

Gregory DeAngelo

Bryan C. McCannon

Working Paper No. 16-14

This paper can be found at the College of Business and Economics

Working Paper Series homepage: 


\title{
Honest Abe or Doc Holliday? Bluffing in Bargaining
}

\author{
Gregory DeAngelo \\ West Virginia University \\ Bryan C. McCannon \\ West Virginia University
}

17 February $2016^{*}$

\begin{abstract}
:
We consider a bargaining environment where there is asymmetric information regarding whether the two players have common preferences or conflicting preferences. If the cost of strategic communication is independent of the state, then signaling is not expected to be effective. If the uninformed agent believes, though, a (cheap-talk) signal has been sent, then the informed agents are incentivized to engage in deceptive bluffing. Alternatively, if bluffing is not too prevalent, honest communication can be worthwhile. We explore this theoretically and experimentally. We present a bargaining model where state-dependent mixed strategies arise as equilibria. Thus, bluffing occurs in equilibrium. In the model, players who experience a disutility to engaging in deceptive behavior are then introduced. The set of equilibria are refined and we show, ironically, that the introduction of honest players increases the overall level of deception. We then design an experimental game to assess the validity of the predictions from the theoretical model. We show that agents attempt to strategically transmit information even when (costly) signaling is not possible. Across rounds of the game honest, but cheap talk, signaling and bluffing co-move in that as the former becomes more prevalent so too does the latter. Furthermore, we document a contagion effect in the laboratory. Bluffing not only creates deadweight loss in a particular dyad, but leads the agent who was bluffed to engage in more bargaining conflict in future rounds against a new, randomly-selected opponent. Aggregate wealth is higher prior to the introduction of deception in the group.
\end{abstract}

Keywords: bargaining, bluff, cheap-talk signaling, contagion, deception, experiment, signal, strategic information transmission

\footnotetext{
* We thank Mark Wilson and Kim McCannon for research assistance conducting the experimental. We also appreciate the comments and suggestions from Siddhartha Bandyopadhyay, Collin Raymond, Andy Young, as well as seminar participants at West Virginia University. We also appreciate the financial support provided by the Koch Foundation.
} 


\section{Introduction}

Consider an assistant district attorney whose job it is to process hundreds of criminal cases every year. ${ }^{1}$ The prosecutor wants to dispense justice by obtaining appropriate sanctions for the guilty, screen out those not culpable, and clear off as much of the backlog as possible. The vast majority of the cases involve guilty individuals with sufficient evidence to get a conviction at trial. Many are routine cases where reasonable expectations can be formed on what the sentence will be when convicted. In this environment most cases receive a plea bargain which rewards the defendant for saving the prosecutor time, effort, and resources by offering a plea discount. Occasionally, though, a defense attorney may come with a claim that his client, contrary to the suggestion of the evidence, is actually innocent. ${ }^{2}$ How does the prosecutor respond? If the attorney is being honest, then it is in both party's interest to dismiss the charges. If it is a bluff, then not only does a criminal go unpunished, but defense attorneys in future cases may be incentivized to bluff as well. Should the prosecutor ignore all such pleas?

While a specific, hypothetical scenario, the dilemma being described arises in numerous bargaining environments. Private information is held by one side to the negotiation. This private information is in regards to whether the scenario is a true adversarial environment of conflicting preferences, or whether it is one of common preferences where both share the same objective. While communication is possible, it is cheap talk in that signals attempted are symmetrically costless. If the attempt at honest communication is ignored, then bluffing is ineffectual. Communication breaks down and the uninformed party is left to respond to her ex ante beliefs. Examples of bargaining similar to those described include renegotiations with suppliers due to increased costs when the purchaser cares about the long-run solvency of suppliers (Loch and $\mathrm{Wu}, 2008$ ), regulation of utilities when regulators care about low consumer prices and costs to energy production (Leaver, 2009), and a real-estate agent

\footnotetext{
${ }^{1}$ For example, in a comprehensive survey of all 2330 state-level prosecutor offices in the United States, the average number of closed cases per prosecutor (for offices with at least four prosecutors employed) is 124.3 felonies per year. Thus, the typical assistant district attorney closes approximately 2.5 felony cases each week (see Detotto and McCannon (2016) for a discussion of the data).

${ }^{2}$ Hard evidence (verifiable and believable) of innocence may not be transferrable. See Bibas (2011) for an example of a discussion of the difficulty and lack of motivation for full information disclosure during plea bargaining and Farmer and Pecorino (2013) for a theoretical investigation.
} 
encouraging a seller to accept an offer arguing that market demand is weak as opposed to an agent who is bluffing to turn over her inventory and quickly obtain the commission (Levitt and Syverson, 2008).

Public servants in regulatory positions are often put in the position of bargaining with the regulated in several critical environments. Furthermore, it has been long recognized that market interactions trade-off competition and cooperation, or rather, engage in "co-opetition" (Bradenburger and Nalebuff, 1997). The objective of this study is to appreciate the role and effectiveness of strategic information transmission in these environments.

Whether negotiating in the legal system, regulatory environments, supply chain, or with thirdparty intermediation, bargaining is both costly and uncertain. We explore both theoretically and experimentally the potential for bluffing and honest communication. We first develop a simplified bargaining environment where there is asymmetric information regarding whether the parties have common or conflicting preferences. When they have common preferences, the informed agent would like to share this information. Without state-dependent costs, (standard) signaling is ineffective. Thus, any attempt to honestly convey this information through one's choices is referred to here as cheap-talk signaling. ${ }^{3}$ When the players have conflicting preferences, the informed agent would like to misrepresent the state through his actions, or rather, bluff. We show that state-dependent offers are made and accepted. Thus, bluffing and cheap-talk signaling occur in equilibrium with a positive probability. An agent, with knowledge that they have common preferences, attempts to convey this by requesting an outcome that is agreeable to both only if they indeed have common preferences. This, if believed, encourages bluffing when the state is one of conflicting preferences. Thus, cheap-talk signals encourage bluffing. In equilibrium, cheap-talk signaling is not so frequent as to encourage bluffing with probability one, but frequent enough to be informative, given the bluffing it incentivizes. The equilibria can be Pareto-ranked and differ in the total number of rejected offers. We then add honest agents, which we refer to as "Honest Abes", who experience a disutility from misrepresentation and show that this refines the set of equilibria and, ironically, leads to more deception in the negotiations.

We then test the empirical validity of the theory by designing an alternating-offers bargaining game with asymmetric information on the payoff functions. Treatments vary by the costs associated

\footnotetext{
${ }^{3}$ Throughout we refer to the state-contingent play where the informed agent, with knowledge that the true state is one of common preferences, attempts to convey this information through "extreme" actions as cheap-talk signaling. This is to separate it from standard signaling using costly actions, Spence (1973), and pre-play, cheap talk communication, as introduced by Crawford and Sobel (1982). In the presentation of both the theoretical model and experimental method a precise definition for each context, respectively, will be given.
} 
with bargaining conflict and the stakes of the negotiation, both of which are predicted by the theoretical model to affect the frequency of cheap-talk signaling and bluffing. Results from the laboratory experiment conform to the theory. Both cheap-talk signaling and bluffing occur. As cheap-talk signaling increases in frequency in the sessions, bluffing too increases in prevalence. Furthermore, we document a contagion effect of bluffing. Subjects who experience a bluff in a round are more likely to engage in bluffing themselves in the future, increasing conflict and deadweight loss. Comparisons of subjects who engage in bluffing (the "Doc Hollidays") show that they are qualitatively different individuals from those prone to be Honest Abes. ${ }^{4}$

The only other paper that has theoretically investigated deception in bargaining is Holm (2010). ${ }^{5}$ He considers bluffing and truth-telling in a simple, one-shot game. He models a game with conflicting preferences where the receiver has the ability to detect a lie or the truth with a positive probability. There is a related theoretical literature on strategic lying in (costly) signaling environments (Kartik, 2009). ${ }^{6}$ We contribute to this research line by extending the study of deceptive behavior beyond standard signaling situations.

An important related literature is the cheap-talk theory of pre-play communication pioneered by Crawford and Sobel (1983). They illustrate the value of pre-play, costless messaging. In their environment, communication can be effective when the payoffs of the players are sufficiently similar. A number of important extensions to this environment have been explored, such as "burning money" (Austen-Smith and Banks, 2000; Kartik, 2007) and naïve, credulous receivers of the information (Kartik, Ottaviani, and Squintani, 2007). The important distinction between this environment and ours is that we do not allow for an initial messaging game. Communication in our setting occurs through extreme actions. A counteroffer in a negotiation can be informative if it asks for an amount that would only be agreeable to the uninformed party if the privately held information indicates that it is in both of their interests to agree to the extreme offer (e.g. a request of a case dismissal by a defense attorney).

We are not the first to document intentional deceptive behavior in the laboratory. Brandts and Charness (2003) document experimental evidence that one's willingness to punish an unfair action is sensitive to whether the action was preceded by a deceptive message. Gneezy (2005) provides evidence

\footnotetext{
${ }^{4}$ Honest Abe is a nicknamed given to the U.S. President Abraham Lincoln referencing the belief that he could never tell a lie. Doc Holliday was a famous poker player in the Wild West of the U.S. in the late 1800s.

${ }^{5}$ Experimental investigation of truth detection is considered in Holm (2004).

${ }^{6}$ Applications include signaling of platforms by politicians (Callander and Wilkie, 2007; Kartik and McAfee, 2007) and the distortion of criminal evidence (McCannon, 2011).
} 
that individual's willingness to lie depends on the benefits relative to the costs imposed on the deceived, which is further analyzed by Hurkens and Kartik (2007). Charness and Dufwenberg (2006) consider a game where subjects can make non-enforceable promises via communication, but renege on them. While they are cheap talk, promises are made and believed by the subjects. Similarly, Duffy and Feltovich (2006) consider a messaging game where subjects can communicate intended actions. They vary treatments by whether receivers of the message observe whether the subject lied in the past. Wang, Spezio, and Camerer (2010) report data using eyetracking and document that senders do not look at the receiver's payoff very often and that their pupils dilate when deceptive signals are sent. SerraGarcia, van Damme, and Potters (2013) consider deceptive messaging in a Public Goods Game and Chen and Houser (2013) consider it in a Trust Game. Truth bias is detected in experiments by Kawagoe and Takizawa (2009). Thus, the experimental research that has been conducted has not focused on bargaining and bluffing through one's action, but through games with deception via untrue messages. Boles, Croson, and Murnigham (2000) and Croson, Boles, and Murnigham (2003) do consider repeated ultimatum bargaining games where resources available are asymmetrically known. Messaging, again, provides the opportunity to deceive. Thus, our distinct contribution is to document bluffing behaviors, rather than deceptive costless messaging, and to highlight its diseasing effect in a population.

Section 2 presents the theory. Section 3 describes the experimental methods employed, while Section 4 presents the econometric results. Section 5 concludes.

\section{Theory}

We proceed by providing a simplified bargaining environment. The objective is to capture the tradeoff that exists between trying to truthfully communicate the state of the world versus deceptively misrepresenting the situation. The back-and-forth nature of bargaining is suppressed and the range of possible offers and counteroffers is narrowed to two exogenous levels. These reductions in the environment, though, are done to provide a tractable framework to evaluate the information transmission mechanism. 


\subsection{Theoretical Framework}

Suppose there are two players engaged in a negotiation: Player A and Player B. Player A has made an offer to B of $\omega$, which will be taken as exogenous. Player B must decide to either accept or reject the offer. Let the probability $B$ chooses to accept the offer be denoted $\beta$. If Player B accepts the offer, then the game is over. Alternatively, if Player B rejects the offer, then a counteroffer of $\Omega$ is made. Again, the size of the counteroffer is taken as exogenous so that Player B's decision is binary. Following the derivation of the equilibria, the consequence of changes in the offer and counteroffer will be explored. Furthermore, the rejection of the offer prolongs the conflict and, consequently, costs are incurred by both players. These costs include the direct transaction costs associated with continued negotiations, but also the opportunity costs of lost time that could have been devoted to other enterprises. Let $C_{i}$ denote the cost to player $i$ of the rejection. Finally, if $\mathrm{B}$ makes a counteroffer, Player $\mathrm{A}$ makes the decision to accept or reject $\Omega$. Let $\alpha$ denote the probability Player $A$ accepts the offer. If Player $A$ accepts the offer then $\Omega$ is the outcome, but if A rejects the offer then the outcome is $Z$. Thus, the possibility of $B$ rejecting again and countering the counteroffer (and the string of possible back-andforth negotiations) is suppressed and the expected outcome summarized by the exogenous parameter $Z$. One may think of $Z$ as the expected outcome, at Player A's decision node, regarding the future alternating-offers behaviors. Furthermore, if Player B accepts Player A's opening offer, then there are no more decisions for $A$ to take. Thus, the selection of $\alpha$ only arises when $\beta<1$.

Regarding the payoffs, suppose there are two states of the world, $\Sigma=\{n, m\}$, where the state $s=$ $n$ represents conflicting preferences between the two players and $s=m$ indicates common preferences. Let $\sigma$ denote the (common) prior beliefs regarding the state. Specifically, let $\sigma>1 / 2$ be the probability $s=$ $n$. Regardless of the state, the payoff to Player $B$ is $u_{b}=X-(1-\beta) C_{b}$ where $X \in\{\Omega, \omega, Z\}$. Thus, $B$ wants the agreed upon outcome to be as high as possible, but also suffers a disutility from conflict. For Player A if $s=n$, then $u_{a}(n)=W-X-(1-\beta) C_{a}$ where $W$ is an endowment. Thus, with conflicting preferences, one can think of the negotiation as a mechanism to divide the endowment $W$ between the two players where, $X$ is the division of the pie B receives. Instead, if $s=m$, then the two players have common preferences. In this case, $u_{a}(m)=W+X-(1-\beta) C_{a}$. Hence, with common preferences, both players want $X$ to be as large as possible. Assume $W>\Omega>\omega>Z \geq 0$. 
The environment presented is sufficiently general so that it can apply to numerous bargaining environments with asymmetric information. For example, in the criminal justice system, the outcome $X$ can be thought of as the plea discount - the reduction in the sentence obtained by agreeing to plead guilty. The outcome $Z$ captures the expected outcome if the case goes to trial and $W$ is the sanction that arises conditional on conviction (from, for example, sentencing guideline tables). With a small probability the defendant is actually innocent and both parties want to reduce the sentence and, ideally, dismiss the charges $(\Omega=W)$. While a very high counteroffer may attempt to signal innocence by the defendant, such an action from a guilty criminal can be thought of as a bluff. In supply-chain renegotiations the outcome $X$ can be thought of as the size of the contract price increase where, with a small probability, the bankruptcy of the supplier harms the final good manufacturer as the switching costs associated with finding a new supplier are high. In this scenario the manufacturer prefers to increase the contract price. Similar mappings can be made to the regulatory or third-party intermediation environments, along with any realistic scenario where there is asymmetric information in bargaining over the validity of conflicting preferences.

In this theoretical environment, rejecting when the state is of common preferences $(s=m)$ and countering with a large request $(\Omega)$ is advantageous when the player believes the receiver will likely accept, or rather, believes that the state is $m$. Hence, the offeror engages in cheap-talk signaling. Alternatively, rejecting the initial offer when there are conflicting preferences $(s=n)$, again countering with a large request $(\Omega)$ is profitable when the receiver of the offer incorrectly believes the state is $m$. Such an action is referred to as, in this environment, bluffing.

\subsection{Equilibrium}

In the Perfect Bayesian Nash Equilibrium, Player A accepts the offer when $\sigma^{\prime}\left[W-\Omega-(1-\beta) C_{a}\right]+$ $\left(1-\sigma^{\prime}\right)\left[W+\Omega-(1-\beta) C_{a}\right]>\sigma^{\prime}\left[W-Z-(1-\beta) C_{a}\right]+\left(1-\sigma^{\prime}\right)\left[W+Z-(1-\beta) C_{a}\right]$, or rather, $W+\left(1-2 \sigma^{\prime}\right) \Omega-$ $(1-\beta) C_{a}>\mathrm{W}+\left(1-2 \sigma^{\prime}\right) Z-(1-\beta) C_{a}$ where $\sigma^{\prime}$ is the updated probability that $s=n$. This simplifies to choosing to accept an offer when $\left(1-2 \sigma^{\prime}\right) \Omega>\left(1-2 \sigma^{\prime}\right) Z$. Thus, the best response for Player $A$ is 


$$
\alpha=\left\{\begin{array}{cl}
0 & \text { if } \sigma^{\prime}>1 / 2 \\
{[0,1]} & \text { if } \sigma^{\prime}=1 / 2 \\
1 & \text { if } \sigma^{\prime}<1 / 2
\end{array}\right.
$$

Now consider the decision made by Player B. If Player B accepts the offer, it receives $\omega$.

Alternatively, it receives $\alpha \Omega+(1-\alpha) Z-C_{b}$ if it rejects. Hence, accepting the initial offer is better when $\alpha$ $<\alpha^{*}$ where $^{7}$

$$
\alpha^{*} \equiv\left[\omega-Z+C_{b}\right] /(\Omega-Z)
$$

Thus, the best response for Player B is

$$
\beta=\left\{\begin{array}{cl}
0 & \text { if } \alpha>\alpha^{*} \\
{[0,1]} & \text { if } \alpha=\alpha^{*} \\
1 & \text { if } \alpha<\alpha^{*}
\end{array}\right.
$$

Therefore, conditioning on $\sigma^{\prime},(1)$ and (3) are the best response correspondences.

Finally, consider the beliefs of Player A. If the decision by Player B does not depend on the state of the world, then there will not be a difference in decision making by B. Suppose, then, that Player B's response is determined by the state. Specifically, let $\beta_{s}$ denote the probability Player $B$ accepts the initial offer when the state is $s$. If this is indeed the behavior, then Player A's updated probability of the state when the offer is rejected is

$$
\sigma^{\prime}=\sigma\left(1-\beta_{n}\right) /\left[\sigma\left(1-\beta_{n}\right)+(1-\sigma)\left(1-\beta_{m}\right)\right]
$$

\footnotetext{
${ }^{7}$ Assume $C_{b}<\Omega-\omega$ so that $\alpha^{*}<1$. If the cost to continue conflict in bargaining is too high, then Player $\mathrm{B}$ must accept the initial offer regardless of the decision to be made by Player $A$.
} 
The existence of a (non-degenerate) mixed strategy Bayesian Nash Equilibrium requires, from (1), that $\sigma^{\prime}$ $=1 / 2=\sigma\left(1-\beta_{n}\right) /\left[\sigma\left(1-\beta_{n}\right)+(1-\sigma)\left(1-\beta_{m}\right)\right]$, which simplifies to $2 \sigma\left(1-\beta_{n}\right)=\sigma\left(1-\beta_{n}\right)+(1-\sigma)\left(1-\beta_{m}\right)$, or rather,

$$
\sigma\left(1-\beta_{n}\right)=(1-\sigma)\left(1-\beta_{m}\right)
$$

Hence, the set of Perfect Bayesian Nash Equilibria are defined by $\alpha=\alpha^{*}$, provided in (2), any combination of $\beta_{n}$ and $\beta_{m}$ which satisfy (5), and beliefs described by (4).

Notice that since $\sigma>1 / 2, \beta_{n} \geq \beta_{m}$ in all proposed equilibrium (and they are equivalent only when both are equal to one). Furthermore, the lower bound for $\beta_{n}$ is $(2 \sigma-1) / \sigma$, such that $\beta_{n} \in[(2 \sigma-1) / \sigma, 1]$ while $\beta_{m} \in[0,1]$. Therefore, a combination of plays for the Player $B$ in the two states of the world that satisfy this equality, (5), would lead to $\alpha=\alpha^{*}$ as being the best response for Player $A$. As a result, Player B in state $n$ would find $\beta_{\mathrm{n}}$ to be a best response, and Player B in state $m$ would find $\beta_{\mathrm{m}}$ to be a best response.

In this framework, a bluff occurs when Player B rejects the offer demanding a higher offer when they, in fact, have conflicting preferences. Thus, a bluff occurs with probability $\sigma\left(1-\beta_{n}\right)$. Alternatively, a cheap-talk signal is sent when Player B rejects the offer requesting a higher one, and they have common preferences. This occurs with probability $(1-\sigma)\left(1-\beta_{m}\right)$. The two outcomes are equally likely in equilibrium, (5). The set of equilibrium includes $\beta_{m}=\beta_{n}=1$ where all initial offers are accepted and no strategic communication is attempted. ${ }^{8}$

Therefore, bluffing and cheap-talk signaling can occur in equilibrium. It requires that the distortion of the quality of the information caused by bluffing is great enough to make Player $A$ believe it is a 50-50 chance that the rejection comes when there is conflicting versus common preferences. Conditional on the state of the world, cheap-talk signaling should be more frequently observed than bluffing and, therefore, as a result, total rejections should be greater when the players have common preferences. Also, the equilibrium level of acceptance of counteroffers by Player $A, \alpha^{*}$, depends on the

\footnotetext{
${ }^{8}$ In all other equilibria, Player A's decision node is reached with a positive probability. Thus, out-of-equilibrium beliefs need not be defined. Here, though, the equilibrium utilizes $\sigma$ ' still defined as in (4) for the out-ofequilibrium beliefs. Numerous alternative beliefs could be held that rationalize $\beta_{n}=\beta_{m}=1$ as best responses, but beliefs that result in $\beta_{n}, \beta_{m}<1$ must be those defined in (4) to be Perfect Bayesian Nash equilibria.
} 
size of the opening offer $(\omega)$, the cost of Player B's rejection $\left(C_{b}\right)$, and the stakes involved, $(\Omega-Z$ and $\omega-$ Z).

While the theoretical model takes $\omega$ and $\Omega$ as exogenous, in applications it is typically endogenous. We can identify the impact of changes in the two parameters. As with any game with multiple equilibria, one can only discuss how the set of equilibria adjust. First, the set of equilibria choices for Player B is unchanged. The bounds are only determined by the ex ante beliefs of the state, $\sigma$. Thus, the frequency of cheap-talk signaling and bluffing is unaffected by the size of the initial opening offer and counteroffer. An increase in $\omega$, though, increases the equilibrium probability of $A$ accepting a counteroffer, while an increase in $\Omega$ decreases the likelihood. In all equilibria, though, $A$ is indifferent between accepting and rejecting the counteroffer and, thus, since the payoff to rejecting is fixed, A's expected payoff is unaffected in equilibrium by changes in his initial offer (and B's counteroffer). Player B's expected payoff is, of course, improved when the opening offer is more generous, but this is not controlled by B.

\subsection{Introducing Honest Abes}

The previous analysis does not allow for any heterogeneity in the population of potential players, so that, to return to the plea bargaining motivating example, all defense attorneys are the same and have no qualms with misrepresenting and deception. One should be cautious about employing such a pessimistic view of preferences. Also, given that bluffing is destructive in this environment, one might expect outcomes to improve if deceptive individuals are less prevalent. Hence, to extend the framework, suppose there is the possibility of having an Honest Abe as Player B. An Honest Abe experiences a disutility from not telling the truth (i.e., bluffing). Consequently, an Honest Abe's utility function is $u_{b}(s ; H)$ where $u_{b}(m ; H)=X-(1-\beta) C_{b}$ and $u_{b}(n ; H)=X-(1-\beta)\left(C_{b}+\theta\right)$ where $\theta \geq 0$ is the disutility to being dishonest. If $\theta=0$, then the payoff functions are equivalent to the baseline model. A similar assumption is employed in Kartik, Ottaviani, and Squintani (2007), Miettinen (2013), and De Haan, Offerman, and Sloof (2015) and experimental evidence is provided by Gneezy (2005). ${ }^{9}$ Suppose the likelihood that a Player $B$ is an Honest Abe is $\eta$. With probability $1-\eta$ the player does not experience

\footnotetext{
${ }^{9}$ Relatedly, Vanberg (2008) provides experimental evidence consistent with subjects experiencing a benefit from keeping their promises (as opposed to a disutility of letting others down).
} 
any disutility from being dishonest. We will refer to such a player as a Doc Holliday. A Doc Holliday's utility, $u(s ; D)$, remains the same as in the previous section $\left(u_{b}\right)$.

For an Honest Abe, accepting the initial offer is preferable when $\omega \geq \alpha \Omega+(1-\alpha) Z-C_{b}-\theta$, which simplifies to accepting when $\alpha \leq\left[\omega-Z+C_{b}+\theta\right] /(\Omega-Z) \equiv \alpha^{*}{ }_{n}(H)$. Therefore, the best response correspondence for an Honest Abe in state $s=n$ is

$$
\beta_{n}(H)=\left\{\begin{array}{cl}
0 & \text { if } \alpha>\alpha_{n}^{*}(H) \\
{[0,1]} & \text { if } \alpha=\alpha_{n}^{*}(H) \\
1 & \text { if } \alpha<\alpha_{n}^{*}(H)
\end{array}\right.
$$

Since no adjustment has been made to the payoff function for Doc Holliday or Honest Abe when $s=m$, (3) continues to be the best response for them. Furthermore, the best response correspondence for Player A, (1), the updating of beliefs (4), and the equilibrium condition (5), all carry over in this extension.

In this adjusted environment mixed strategy, Perfect Bayesian Nash Equilibrium has either Honest Abes playing a non-degenerate mixed strategy, while the Doc Holliday plays a pure strategy of $\beta(D)=0$ (since $\alpha^{*}(H)>\alpha^{*}$ ), or Doc Holliday plays a non-degenerate mixed strategy, while the Honest Abes play the pure strategy $\beta(H)=1$. Now, in this extension, mixed strategies are both state contingent and type dependent. Therefore, $\beta_{s}=\eta \beta_{s}(H)+(1-\eta) \beta_{s}(D)$ for state $s$.

The equilibrium condition is the same as before, namely $\sigma\left(1-\beta_{n}\right)=(1-\sigma)\left(1-\beta_{m}\right)$. Thus, there are two sets of equilibria. In one set, $\alpha=\alpha^{*}{ }_{n}(H)$. This causes $\beta_{n}(D)=\beta_{m}(D)=\beta_{m}(H)=0$. Thus, $\beta_{n}=\eta \beta_{n}(H)$ and $\beta_{m}=0$. Therefore, the equilibrium condition, (5), holds only when $\beta_{n}=(2 \sigma-1) / \sigma \in(0,1)$ since $\sigma \in(1 / 2$, 1). Thus, there is only one Perfect Bayesian Nash Equilibrium when $\alpha=\alpha^{*}{ }_{n}(H)$; namely $\beta_{n}(D)=\beta_{m}(D)=$ $\beta_{\mathrm{m}}(H)=0$ and $\beta_{\mathrm{n}}(H)=(2 \sigma-1) / \sigma \eta$.

Compare this equilibrium to those which arises if there are no Honest Abes. The equilibrium level of acceptance by Player $A$ is greater. Additionally, the unique equilibrium here is the one with the lowest level of acceptance by Player B when there are no Honest Abes. Thus, bluffing and cheap-talk signaling are maximal. Thus, we get the ironic result that deceptive bargaining escalates when we introduce honest players. Regarding individual behavior, Doc Holliday bluffs and signals with probability 1, whereas without the existence of Honest Abes, this was less than one. Therefore, the entrance of 
Honest Abes into the subject pool increases cheap-talk signaling and bluffing by Doc Hollidays. The Honest Abes also signal, but bluff at a lower rate than any equilibrium if Honest Abes did not exist.

In the second set of equilibria, $\alpha=\alpha^{*}$. Consequently, $\beta_{n}(D), \beta_{m}(D), \beta_{m}(H) \in[0,1]$ and $\beta_{n}(H)=1$ (since $\left.\alpha^{*}<\alpha_{n}^{*}(H)\right)$ As a result, $\beta_{n}=\eta(1)+(1-\eta) \beta_{n}(D)$ and $\beta_{m}=\eta \beta_{m}(H)+(1-\eta) \beta_{m}(D)$. Hence, $\sigma[1-\eta-(1$ $\left.-\eta) \beta_{n}(D)\right]=(1-\sigma)\left(1-\beta_{m}\right)$ is the equilibrium condition that defines Player B's selection. The range of possible equilibrium values of $\beta_{n}(D)$ is $\beta_{n}(D) \in[((1-\eta) \sigma-(1-\sigma)) / \sigma(1-\eta), 1] \supset[(2 \sigma-1) / \sigma, 1] .{ }^{10}$ The range of possible values of $\beta_{m}$ is $\beta_{m} \in[0,1]$. Any combination of $\beta_{m}(D)$ and $\beta_{m}(H)$ that generates a value of $\beta_{\mathrm{m}}$ in this interval is an equilibrium.

For these equilibria, the overall rates of acceptances by Player As and Player Bs are unchanged. That is, the equilibrium level of $\alpha$ is the same here as in Section 2.2 and the set of equilibria $\beta_{n}$ and $\beta_{m}$ are identical in the two models. What does adjust is who engages in strategic information transmission when Honest Abes are added to the population. Consider the comparison in behavior of Doc Holliday with and without Honest Abes in these equilibria. The set of equilibria behaviors in state $s=n$ contains the set without Honest Abes. The mixed strategy which are now equilibria are those with the lower values of $\beta_{n}(D)$. Thus, Doc Holliday is more likely to bluff when conflicting preferences are present. On the other hand, the set of equilibria is unchanged when $s=m$, so there is no expected difference in cheap-talk signaling behavior. Honest Abes do not bluff.

As stated, there are two sets of equilibria when Honest Abes are present. Overall, the common feature of the two sets of equilibria are that bluffing is (weakly) more likely to arise and cheap-talk signaling is non-decreasing with the introduction of Honest Abes. The unconditional amount of rejections by Player $B$ is unaltered, but the non-Honest Abes will reject offers at a higher rate.

\subsection{Welfare and Testable Predictions}

We first consider the welfare implications of the equilibria that we have established. With common preferences, welfare is $W+X-\left(1-\beta_{\mathrm{m}}\right) C_{a}+X-\left(1-\beta_{\mathrm{m}}\right) C_{b}=W+2 X-\left(1-\beta_{\mathrm{m}}\right)\left[C_{a}+C_{b}\right]$, while

\footnotetext{
${ }^{10}$ If $\eta<(1-\sigma) / \sigma$, then the lower bound to $\beta_{\mathrm{n}}(D)$ is strictly greater than 0 . Otherwise, $\beta_{\mathrm{n}}(D) \in[0,1]$.
} 
with conflicting preferences welfare is $W-X-\left(1-\beta_{n}\right) C_{a}+X-\left(1-\beta_{n}\right)\left(C_{b}+\eta \theta\right)=W-\left(1-\beta_{n}\right)\left[C_{a}+C_{b}+\right.$ $\eta \theta]$. Overall, expected welfare is

$$
W+(1-\sigma) 2 \mathrm{E} X-(1-\mathrm{E} \beta)\left(C_{a}+C_{b}\right)-\left(1-\beta_{\mathrm{n}}\right) \sigma \eta \theta
$$

where $E \beta=\sigma \beta_{n}+(1-\sigma) \beta_{m}$ is the weighted acceptance rate and $E X=\beta_{m} \omega+\left(1-\beta_{m}\right)(\alpha \Omega+(1-\alpha) Z)$ is the expected agreed upon outcome. This is the welfare for both the base model (setting $\theta=0$ ) and the Honest Abe extension. Therefore, expected welfare is greater when exogenous factors adjust, such as when (i) the stakes are greater ( $E X$, or rather, $\Omega-Z$ and $\omega-Z)$ and (ii) the costs of conflict are lower $\left(C_{a}\right.$, $C_{b}$, and $\theta$ ). Similarly, expected welfare improves when (iii) the rate of acceptance by Player $A$ is higher (i.e., expected welfare is increasing in $\alpha$ ) and (iv) the acceptance by Player B when the two have conflicting preferences is more likely (i.e., expected welfare is increasing in $\beta_{n}$ ). These are partial effects, though. The impact of adjusting $\beta_{m}$ on expected welfare depends on the behavior of Player $A, \alpha$. If $A$ is sufficiently likely to accept the counteroffer, then accepting the initial offer is counterproductive for both parties. On the other hand, if Player $A$ is unlikely to accept, then both individuals benefit from Player B accepting the opening offer. Thus, for illustration, the expected welfare when $\alpha=\beta_{n}=1$ is linear and either strictly increasing or strictly decreasing in $\beta_{\mathrm{m}}$ so that the optimal is at a corner. Expected welfare with $\beta_{m}=1, W+(1-\sigma) 2 \omega$, can be compared to it with $\beta_{m}=0, W+(1-\sigma) 2 \Omega-(1-\sigma)\left(C_{a}+C_{b}\right)$. Therefore, $\beta_{m}=1$ is optimal, given $\alpha=\beta_{n}=1$, when

$$
2(\Omega-\omega) \leq C_{a}+C_{b}
$$

The inequality of (8) illustrates that the welfare implications of rejection depends on the total costs caused and the surplus generated. If this inequality holds, then it is optimal for Player B to not engage in cheap-talk signaling when the players have common preferences. If this inequality does not hold, then social welfare is maximized when cheap-talk is always attempted. Hence, when costs are high and the initial offer is sufficiently generous, rejections are suboptimal from a welfare perspective. 
While the welfare-maximizing outcome depends on the costs and stakes involved in the negotiation, the set of equilibria in the base model can be Pareto-ranked. Recall that, in equilibrium, (5) must hold and all equilibria share the same value of $\alpha, \alpha^{*}$. If we first solve (5) for $\beta_{n}$ and insert it, along with $\alpha^{*}$, into the expected welfare function, it follows that the expected welfare is strictly decreasing in $\beta_{m}$. Thus, the equilibrium of the game (in the base model) with $\beta_{m}=0$ and $\beta_{n}=(2 \sigma-1) / \sigma$ Paretodominates, while the equilibrium with $\beta_{m}=\beta_{n}=1$ is Pareto-inferior.

Now consider the welfare effects of introducing Honest Abes to the pool of potential players. As shown in Section 2.3 there are two "types" of equilibria that arise. In one, the probability of acceptance by Player $A$ remains the same as in the base model, $\alpha^{*}$. Additionally, the set of equilibria $\beta_{m} s$ and $\beta_{n} s$ remain unchanged. What does adjust is who is engaging in strategic information transmission. In all equilibria in this type $\beta_{\mathrm{n}}(H)=1$. Thus, there is no bluffing by Honest Abes and, as a consequence, no impact on welfare driven by the disutility of being dishonest. Thus, in this type of equilibria there is no change in welfare by introducing Honest Abes. In the second type of equilibria, Player A's accept the offers at a higher rate. Additionally, the probability of Player B accepting the initial offer is unique and equal to the lowest from the set of equilibria of the first type. Rather, acceptance by Player B in the equilibrium with $\alpha=\alpha^{*}{ }_{n}(H)$ is (weakly) less than every equilibria with $\alpha=\alpha^{*}$. Thus, a tradeoff exists in the welfare calculation between the costs of rejections and the greater earnings when a common preference is the state. Additionally, bluffing is being done by Honest Abes. Thus, welfare is strictly worse when the disutility experienced by Honest Abes is sufficiently great.

Turning to the expectations of play, the following predictions arise from the theoretical model:

[1] Cheap-talk signaling and bluffing occur ( $\beta_{m}$ and $\beta_{n}$ are (weakly) less than one). There exists, though, a range of equilibria which differ in the rates of the two arising.

[2] Conditional on the realization of the state, the frequency of cheap-talk signaling should exceed the frequency of bluffing by a constant factor $\left(\left[1-\beta_{m}\right] /\left[1-\beta_{n}\right]=\right.$ $(1-\sigma) / \sigma)$.

[3] Rejections should be more prevalent when the players have common preferences than when they have conflicting preferences (the set of equilibria $\beta_{m}$ contains the set of equilibria $\beta_{n}$ ). 
[4] Higher costs for Player B decrease the total number of rejections ( $\alpha^{*}$ is increasing in $C_{b}$ while the set of equilibria $\beta s$ is unchanged).

[5] Higher stakes increase the total number of rejections ( $\alpha^{*}$ is decreasing in $\Omega$ and $\Omega-Z$ (both of which capture the stakes), while the set of equilibria $\beta$ s is unchanged).

While these predictions are based on comparative statics of the model, ${ }^{11}$ a test of the accuracy of the theory is relevant. The alternative hypothesis is the intuition that costless communication (without the possibility of messaging as developed by Crawford and Sobel (1983)) should be treated as "babble." Cheap-talk signaling should not be attempted and, consequently bluffing would be unsuccessful. Further, rejections should not depend on the costs to conflict and the stakes involved, since opening offers are always accepted.

As a final consideration of the theory, the analysis takes the initial offer by Player $A$ as being exogenous. In a more practical bargaining situation this would not be the case. Consider a stage 0 decision where Player $A$, uninformed of the state, selects $\omega$. In effect, Player A selects the equilibrium. Notice that the set of $\beta$ s that exist in equilibrium are not affected by $\omega$, but $\alpha^{*}$ is. In fact, $\alpha^{*}$ is increasing in $\omega$. Player A's payoff is, as stated previously, $u_{a}(n)=W-X-(1-\beta) C_{a}$ if $s=n$ and $u_{a}(m)=W+X-(1-$ $\beta) C_{a}$ if $s=m$. Hence, its expected payoff is $\mathrm{E} u_{a}=W-\sigma \mathrm{E} X+(1-\sigma) \mathrm{E} X-(1-\beta) C_{a}=W-(2 \sigma-1) \mathrm{E} X-(1-$ $\beta) C_{a}$ where, again, $E X=\beta \omega+(1-\beta)(\alpha \Omega+(1-\alpha) Z)$ is the expected agreed upon outcome. Since $E X$ is increasing in $\omega$ and $E u_{a}$ is decreasing in $X$, the best response for Player $A$ is to offer $\omega^{*}=Z$ since the model assumes $\omega \geq Z$.

This assumes that Player B's response to the change in $\omega$ is to be unresponsive. While directly, $\omega$ does not enter into the derivation of the bounds to the set of equilibria, theory is unable to predict which equilibria outcome is chosen. Therefore, it is perfectly reasonable to conjecture that, for example, Player $B$ selects an equilibrium with a higher value of $\beta$ when $\omega$ increases. If, indeed, this occurs then an increase in the initial offer can be advantageous for Player A and non-minimal offers may arise. While not a test of the theory, empirical observations of bargaining can assess the validity of this presumption.

\footnotetext{
${ }^{11}$ These predictions are consistent with both the base model of Section $2.1 / 2.2$ and the extension with Honest Abes of Section 2.3.
} 


\section{Experiment}

The theoretical model provides testable outcomes. These predictions are outlined in [1] - [5] in Section 2.4. In a bargaining environment where offers can be either accepted or rejected and countered (at a cost), bluffing and cheap-talk signaling would be expected to arise. A variety of equilibria exist which differ in the likelihood of the strategic information transmission being attempted where deadweight loss (via rejected offers) is greater as more communication is attempted. The costs associated with conflict and the stakes involved are predicted to be important determinants of the rate of bluffing and cheap-talk signaling. We develop a laboratory game to capture these features in order to examine whether these testable predictions can be confirmed. The alternative hypothesis, from a standard cheap-talk argument, would be that communication should be uninformative and, therefore, both not be attempted and not be believed if attempted. First, we describe the methods employed to test these hypotheses.

\subsection{Methods}

The presentation of the design of the experiment is broken into descriptions of the subjects, design, procedure, and additional assessments.

\subsubsection{Subjects}

We conducted experiments with undergraduate students at a small, private university in upstate New York, Saint Bonaventure University. Subjects were recruited from classes within the business school, targeting students in both classes taken by under- and upper-classmen. An online reservation manager was used to recruit and schedule the sessions. A total of 117 subjects participated in the six sessions. Each experimental session lasted approximately one hour and was conducted during several evenings in February and March of 2015. Within each session subjects completed three tasks. After providing informed, signed consent, subjects engaged in the experiment. Second, three assessments were completed. Finally, subjects answered a background information questionnaire. 


\subsubsection{Game Design}

Subjects participated in an asymmetric information, alternating-offers bargaining game. In this game, one subject takes on the role of "Player A", while a second is "Player B." Player A must decide how to divide an endowment, $W$. Player A makes an offer, $X_{1}$, to Player B. Player B has the option to accept the offer, ending the game, or to reject and make a counteroffer, $X_{2}{ }^{12}$ In this scenario, Player $A$ has the option to accept the request, ending the game, or reject $X_{2}$ and counter the counteroffer, $X_{3}$. The game continues until one of the players accepts a proposal or $J$ rejections occur.

Regarding payoffs to the game, each rejection costs Player $i, C_{i}$. With probability $\sigma$ the players have conflicting preferences in that the utility to Player $\mathrm{A}$ of agreeing to $X$ with $R$ rejections in total $(R<$ $J)$ is $u_{a}(X, R)=W-X-C_{a} R$. In contrast, Player B receives $u_{b}(X, R)=X-C_{b} R$. In other words, with probability $\sigma$ the bargaining game is one of dividing a pie. ${ }^{13}$ If $R=J$, then $u_{a}(X, J)=-C_{a} J$ and $u_{b}(X, J)=-$ $J C_{B}$. Alternatively, with probability $1-\sigma$ the players have common preferences in that the utility to Player $\mathrm{A}$ is $u_{a}(X, R)=X-C_{a} R$ and the utility to Player $\mathrm{B}$ is, again, $u_{b}(X, R)=X-C_{b} R$ (so long as $\left.R<J\right)$. As a result, $\mathrm{E} u_{a}(X, R)=\sigma W+(1-2 \sigma) X-C_{a} R$. Since $\sigma>1 / 2, E u_{a}$ is decreasing in $X$. Only Player $\mathrm{B}$ is informed of whether the game is one of conflicting or common preferences, but the informed Player B's utility does not depend on this information. Thus, there is no possibility of standard, costly signaling of this information.

In the experiment conducted, two of the parameters are manipulated. First, we introduce a high stakes game $(W=120)$ and a low stakes game $(W=60) \cdot{ }^{14}$ Also, a low cost treatment of $C_{a}=C_{b}=5$, and a high cost treatment $C_{a}=5$ and $C_{b}=10$ are implemented. The theoretical model predicts that, specifically, the magnitude of the cost to Player B drives equilibrium behavior (Prediction [4]). Thus, our treatments differ in only this cost, maintaining Player A's costs the same throughout. In our experiment we fix the likelihood that subjects have common preferences to twenty percent $(\sigma=4 / 5)$. Thus, four

\footnotetext{
${ }^{12}$ Thus, to connect the experimental design to the theory, $X_{1}=\omega$ and $X_{2}=\Omega$.

${ }^{13}$ If $\sigma=1$, then the game is the classic Rubinstein (1982) alternating-offers bargaining game with the common experimental adjustments of a flat penalty for delay/conflict rather than a proportional penalty (see, for example, Zwick and Chen (1999), Sterbenz and Phillips (2001), and McCannon and Stevens (2015) for examples in experimental economics and management). Furthermore, with $\sigma=1$ and $J=1$, then the game decomposes into the classic Ultimatum Bargaining Game.

${ }^{14}$ This allows for $\Omega-Z$ and $\omega-Z$ to be larger to test (5) in the list of predictions from the theoretical model.
} 
treatments are considered: low stakes - low costs, low stakes - high costs, high stakes - low costs, and high stakes - high costs. ${ }^{15}$

\subsubsection{Procedure}

In all six sessions the subjects completed two rounds of each of the four treatments resulting in a total of eight rounds of play. Subjects assigned to the role of Player A in a round took the role of Player $B$ in the next. In sessions 1,3 , and 5 the subjects played the treatments in the order of low stakes - low costs, low stakes - high costs, high stakes - low costs, and high stakes - high costs, while in sessions 2, 4, and 6 the subjects played high stakes - low costs, high stakes - high costs, low stakes - low costs, and low stakes - high costs, in order.

The sessions were conducted in two rooms. Subjects were randomly assigned to a room. In each round of the game a subject in one room was paired with a subject in the other so that the subjects did not know or see who they were playing with. Numerical IDs were used to preserve confidentiality and promote anonymity. In each round of play subjects were randomly paired so that history and reputation cannot affect play. In sessions with an odd number of subjects, one was selected at random to sit out each round. No player sat out more than one round.

Each session began, after introductions and informed consent, with a description of the game. Printed instructions were distributed and PowerPoint slides were presented to provide the rules. The script used is provided in the appendix. After explanation of the game, subjects were given the opportunity and encouraged to ask questions.

To determine whether the game was one of conflicting or common preferences, the playing cards 10, Jack, Queen, King, and Ace were used. Each individual taking the role of Player B (privately) selected a card (with replacement). Players in both rooms were informed that if the Ace was drawn by Player $B$ in the pairing, then they both receive the amount agreed to, $X$, minus any penalties from rejections. If another card is drawn by Player $B$, then $B$ receives $X$ and Player A receives the residual, $W-$ $X$, minus the penalty from rejections. Multiple hypothetical examples were given to make the payoffs and mechanics of the game clear.

\footnotetext{
${ }^{15}$ In all but the low stakes - asymmetric cost treatment it follows that $J=6$ (where the endowment would be exhausted in the low stakes - symmetric cost treatment, $J\left(C_{a}+C_{b}\right)=W$. In the low stakes - asymmetric cost treatment $J=4$.
} 
The offer made by Player A was written down, collected by the researchers, and posted on a Google Docs spreadsheet, which was visible to subjects in both rooms. Player B observed the offer made by his/her partner and wrote down which card s/he drew along with his/her decision, either to accept the offer or to reject and counteroffer. The decision was posted on the spreadsheet so the partner immediately learned the decision (but not the identity of the card). The decisions bounced back and forth between the two players until an agreement was reached or the maximum rejections occurred. After all groups reached an outcome, Player A was informed whether or not Player B had an Ace before proceeding to the next round. As stated, new pairings were made in each round and the players rotated between the role of $A$ and $B$.

From this procedure a number of measureable variables arise. For a pairing with individual $i$ in the role of Player A and individual $j$ in the role of Player B, Rejections $s_{i j}$ measures the number of rejected offers that occurred. Rejections $s_{i j}$ captures the amount of conflict, or rather the deadweight loss, which arose. Predictions [3], [4], and [5] from the theoretical model all make statements in regard to the number of rejections. Also, the number of rejections is a main determinant of welfare. Specifically, the equilibria in the model can be Pareto ranked and the ranking is ordered by the number of rejected offers. Furthermore, the analysis considers the opening offer made by Player $A$, normalized by the size of the endowment, Open ${ }_{i}$. An indicator variable Reject $_{j}$ is set equal to one if Player B rejects A's opening offer. Thus, Open $n_{i}$ and Reject $_{j}$ are the initial decisions of the players ( $\omega$ and $\beta$ in the theoretical model). Furthermore, to capture strategic information transmission, the variable Bluff $f_{i j}$ equals one if and only if Player B did not draw an Ace, rejected the opening offer of Player A (Reject $\left.t_{j}=1\right)$, and countered with an offer strictly greater than three-fourths of the endowment (either greater than 40 when $W=60$ or greater than 90 when $W=120$ ). Similarly, the variable Signal ${ }_{i j}$ equals one if and only if Player $B$ drew an Ace, rejected the opening offer of Player $\mathrm{A}\left(\right.$ Reject $\left._{j}=1\right)$, and countered with a request strictly greater than three-fourths of the endowment. In the findings section we illustrate that the main results are not sensitive to the precise cutoff level of three-fourths.

Finally, before the first round of play, subjects were informed that they would be financially compensated. Specifically, they were informed that a minimum payment of $\$ 10$ would be earned, as a guaranteed profit for participating. They were also told that they could earn more as they played the games, but how much they earned depended on their decisions, choices made by others, and luck. One round of the game was selected at random and the subjects were informed that the number of points earned in that round would be converted into real dollars at the exchange rate of 2 points $=\$ 1$. 


\subsubsection{Assessments}

The second component of each experimental session was the completion of two assessments. They are common evaluation tools used to assess preferences for decision making under uncertainty. First, to gauge subject's risk preferences, the tool developed by Holt and Laury (2002) was given. Specifically, the exact same set of choices and payoffs as used in Deck, Lee, Reyes, and Rosen (2012) and McCannon, Tokar Asaad, and Wilson (2015) was administered. In the risk assessment, subjects made ten separate choices. For each choice two lotteries were presented and the subject selected the one he or she preferred. The first option was for a relatively safer gamble where either 10 or 8 points could be earned. The second option was for a riskier lottery receiving either 19.25 or 0.50 points. The ten choices differed in the probability of obtaining the higher of the two outcomes. A random number generator selected an integer between one and ten to determine which outcome arose. Table 1 presents the risk assessment used. 
TABLE 1: Risk Assessment

Option (a)

\begin{tabular}{|c|c|c|c|c|}
\hline \multirow[t]{2}{*}{ Choice 1} & 10 & if $X$ & 19.25 & if $X$ \\
\hline & 8 & if $1,2,3,4,5,6,7,8,9,10$ & 0.50 & if $1,2,3,4,5,6,7,8,9,10$ \\
\hline \multirow[t]{2}{*}{ Choice 2} & 10 & if 1 & 19.25 & if 1 \\
\hline & 8 & if $2,3,4,5,6,7,8,9,10$ & 0.50 & if $2,3,4,5,6,7,8,9,10$ \\
\hline \multirow[t]{2}{*}{ Choice 3} & 10 & if 1,2 & 19.25 & if 1,2 \\
\hline & 8 & if $3,4,5,6,7,8,9,10$ & 0.50 & if $3,4,5,6,7,8,9,10$ \\
\hline \multirow[t]{2}{*}{ Choice 4} & 10 & if $1,2,3$ & 19.25 & if $1,2,3$ \\
\hline & 8 & if $4,5,6,7,8,9,10$ & 0.50 & if $4,5,6,7,8,9,10$ \\
\hline \multirow[t]{2}{*}{ Choice 5} & 10 & if $1,2,3,4$ & 19.25 & if $1,2,3,4$ \\
\hline & 8 & if $5,6,7,8,9,10$ & 0.50 & if $5,6,7,8,9,10$ \\
\hline \multirow[t]{2}{*}{ Choice 6} & 10 & if $1,2,3,4,5$ & 19.25 & if $1,2,3,4,5$ \\
\hline & 8 & if $6,7,8,9,10$ & 0.50 & if $5,6,7,8,9,10$ \\
\hline \multirow[t]{2}{*}{ Choice 7} & 10 & if $1,2,3,4,5,6$ & 19.25 & if $1,2,3,4,5,6$ \\
\hline & 8 & if $7,8,9,10$ & $\$ 0.50$ & if $7,8,9,10$ \\
\hline \multirow[t]{2}{*}{ Choice 8} & 10 & if $1,2,3,4,5,6,7$ & 19.25 & if $1,2,3,4,5,6,7$ \\
\hline & 8 & if $8,9,10$ & 0.50 & if $8,9,10$ \\
\hline \multirow[t]{2}{*}{ Choice 9} & 10 & if $1,2,3,4,5,6,7,8$ & 19.25 & if $1,2,3,4,5,6,7,8$ \\
\hline & 8 & if 9,10 & 0.50 & if 9,10 \\
\hline \multirow[t]{2}{*}{ Choice 10} & 10 & if $1,2,3,4,5,6,7,8,9$ & 19.25 & if $1,2,3,4,5,6,7,8,9$ \\
\hline & 8 & if 10 & 0.50 & if 10 \\
\hline
\end{tabular}

Option (b)

Thus, a risk neutral individual would select option (a) for the first five choices and option (b) for the last five. A risk averse individual will select (a) for more than five choices and the more risk averse an individual is the more times (a) will be selected. Alternatively, a risk loving subject will select option (a) fewer than five times. We define $S_{a f e_{i}}$ as the number of times option (a) is selected by the subject. ${ }^{16}$ Consequently, as used in previous research on decision making under uncertainty (Deck, Lee, Reyes, and

\footnotetext{
${ }^{16}$ Choice 1 is included to have a ten question instrument but, also, to identify unreliable decision making. In no circumstance did a subject choose (b) for Choice 1.
} 
Rosen, 2012; McCannon, Tokar Asaad, and Wilson, 2015), $S_{a f e}$ is used to measure the degree to which a subject is risk averse in the experiment. ${ }^{17}$

Second, an ambiguity assessment was administered. Specifically, the design created by Halevy (2007) is utilized. In the analysis each subject is confronted with an envelope. Within the envelope is ten playing cards, which are red and black. One card from the envelope is drawn. Each subject must first guess which color is selected. If the card pulled is the same color as he or she guessed, then s/he earns twenty additional points. If the subject guesses incorrectly, s/he receives zero. Before realizing the accuracy of his or her guess, each subject is given the opportunity to sell back the gamble. Each subject selects a number between zero and twenty. The number represents his or her reservation price - the lowest price $s /$ he is willing to accept instead of taking the gamble that $s /$ he correctly guessed the color. A number between zero and twenty is selected at random and if the number selected exceeds the reservation price chosen by the subject, then the subject receives the randomly selected amount rather than experience the lottery. If the randomly selected number is less than the reservation price chosen, then the subject is left with the gamble.

Two envelopes were used and each subject, consequently, made two guesses and chose two reservation prices. In the first envelope, five red and five black cards were inserted. The experimental subjects were informed of this distribution. In the second envelope, the subjects were told there were ten red and black cards in total, but they were not told how many of each color were in the envelope. They knew, though, that there were a total of ten cards in the envelope.

The reservation price selected with Envelope 1 measures risk preferences. A risk neutral individual would be indifferent between a lottery of 0 or 20 with equal probability or receiving 10 with certainty. A selection less than 10 represents a risk averse individual, while a selection greater captures a risk loving individual. Envelope 2 captures ambiguity preferences (Ellsberg, 1961). For a fixed choice for Envelope 1, a decrease in the reservation price for envelope 2 represents an individual who is more averse to ambiguous choices. Table 2 summarizes the assessment.

\footnotetext{
${ }^{17}$ One can be concerned about the behavior of a subject without "standard" risk preferences, since in expected utility theory, regardless of the type of risk preference a person has, a switching point in the decision problem arises. A small portion of the sample switched between (a) and (b) more than once. An indicator variable capturing these subjects can be included in the specification. The results presented in the next section are robust to its inclusion.
} 
Known Information:

Envelope 1

Envelope 2
10 cards -5 red and 5 black

10 cards - red and black (unknown distribution)
Used to Assess...

risk preference

ambiguity preference

Along with a full explanation of the two assessments with numerous examples and an opportunity to ask questions, subjects were informed that they would be financially compensated for their selections. One of the choices in these two assessments was selected at random and the subject would be compensated based on the outcome of that choice. Specifically, they were informed that a random number generator would be used to determine which choice would receive financial compensation. The total monetary gains of a subject in the experiment is comprised of the amount earned in a randomly selected round from the game and the choice between the lotteries made in the randomly-selected decision problem. As stated, a minimum wage was imposed for each subject in each session where we guaranteed that $\$ 10$ would be earned. Thus, subjects earned between $\$ 10$ and $\$ 34$ in the experiment, with a mean payout of $\$ 21.54$.

Finally, at the end of each session, subjects completed a background questionnaire. Basic information was collected. Specifically, their gender, year in school, major, and state of residence was collected. Also, a survey question evaluating their comfort with bargaining was administered. Subjects were asked, on a -2 to +2 Likert scale, to "[r]ate the extent to which you dread versus look forward to negotiating, bargaining, and haggling." The number selected becomes the variable Dread $_{i}$. Table 3 provides variable definitions and descriptive statistics for the background and assessed characteristics of the subjects used in the analysis. 
TABLE 3: Subject Information

$$
(N=117)
$$

\begin{tabular}{|c|c|c|}
\hline Variable & Description & Mean \\
\hline \multicolumn{3}{|c|}{ Background Information } \\
\hline Male & $=1$ if the subject is a woman & 0.594 \\
\hline Foreign & $=1$ if the subject is not from the U.S. & 0.068 \\
\hline$N Y$ & $=1$ if the subject is from New York state & 0.641 \\
\hline Business & $=1$ if the subject is a business major & 0.761 \\
\hline Dread & dread -2 , dislike -1 , neutral 0 , like +1 , look forward to +2 & 0.460 \\
\hline \multicolumn{3}{|l|}{ Assessments } \\
\hline Safe & number of safe selections (out of 10 ) in the risk assessment & 5.840 \\
\hline E1 & reservation price selected with envelope 1 & 10.06 \\
\hline$E 2$ & reservation price selected with envelope 2 & 9.120 \\
\hline
\end{tabular}

The sample is disproportionately men from New York majoring in business, which is due primarily to the recruitment strategy used. Subjects also report a slight preference for bargaining. While the sample average registers risk aversion (Safe $>5$ ) and ambiguity aversion $(E 2<E 1)$, the median individual is risk neutral and ambiguity neutral. As to be expected, the correlation between Safe and E1, along with the correlation between an indicator variable equal to one if Safe $>5$ and an indicator variable equal to one if $E 1<10$, is positive and statistically significant.

\subsection{Descriptive Findings}

Initial findings from the laboratory experiment conform to the theoretical model. Consider, first, the prevalence of bluffing and cheap-talk signaling. In the observed data, as stated, we register a counteroffer as being a bluff if (i) a card other than the Ace was drawn by the subject in the role of Player B and (ii) a counteroffer of strictly more than three-fourths of the endowment is made. We record a counteroffer as being a signal if (i) is replaced with its converse ( $i$ ') an Ace was drawn by the subject in the role of Player B. We feel that the cutoff value use for differentiating bluffs and cheap-talk signals $\left(X_{2}>0.75 \mathrm{~W}\right)$ is satisfactory. Of the set of recorded bluffs and cheap-talk signals, $80.6 \%$ of them 
have a counteroffer request of all of the endowment $\left(X_{2}=W\right) .{ }^{18}$ Only $1.5 \%$ of the observations in the data set make counteroffers between $80 \%$ and $90 \%$ of the endowment. Turning to the prevalence of strategic communication, Figure 1 depicts the rates of bluffing and signaling across the rounds of play.

\section{Figure 1: Information Transmission Across Rounds}

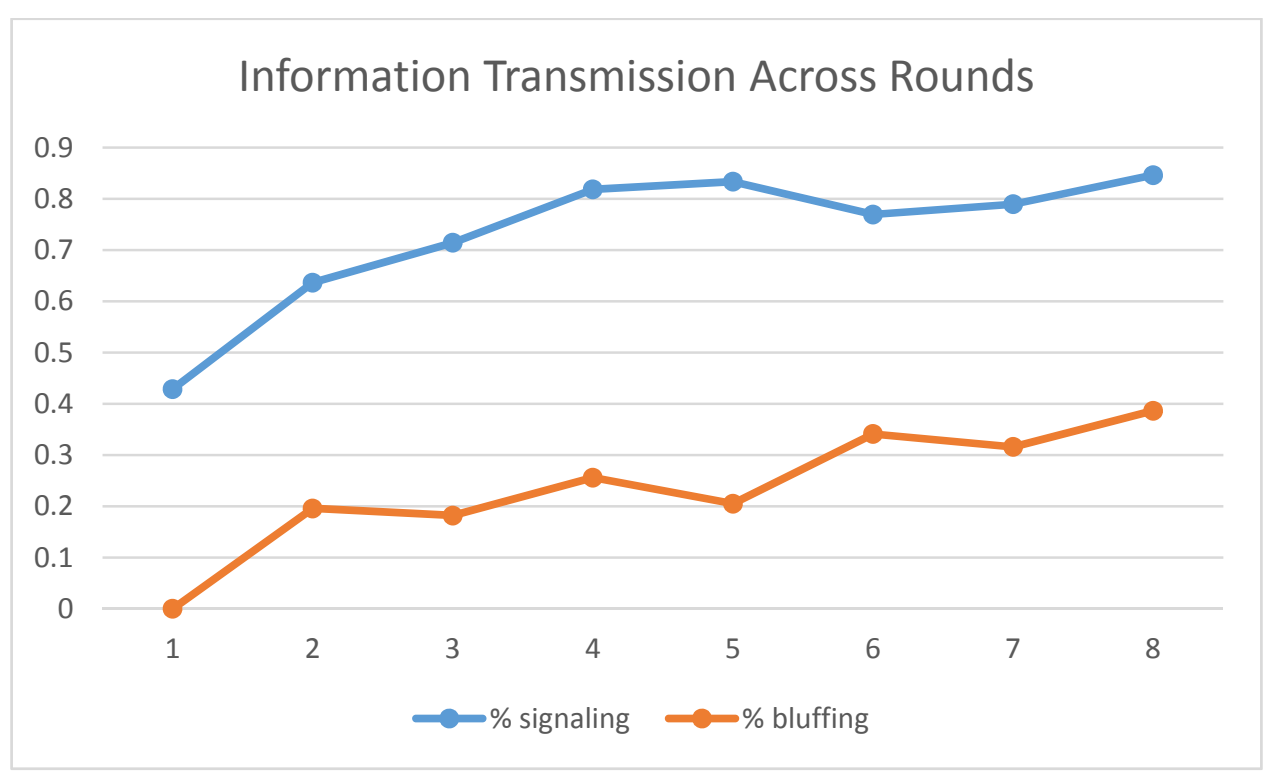

While initially low, the rate of bluffing grows substantially over the rounds. By the second round only $20 \%$ of the pairings without an Ace see a bluff and the proportion grows to nearly $40 \%$ by the final round. Similarly, cheap-talk signaling becomes more prevalent. The proportional change, though, is more modest. Furthermore, the results are consistent with the theoretical model in that the rates of cheap-talk signaling and bluffing should co-move in that higher rates of cheap-talk signaling should encourage higher rates of bluffing. Therefore, hypothesis [1] receives empirical support.

\footnotetext{
${ }^{18}$ There is not a clear pattern to be discerned from the bluffing and cheap-talk signaling via the size of the counteroffer. Of the counteroffers requesting $100 \%$ of the endowment, $45.7 \%$ where bluffs and $50.3 \%$ were cheap-talk signals. Thus, subjects would not be able to (accurately) infer the state from the size of the counteroffer. Given that in equilibrium the unconditional frequency of bluffs and cheap-talk signals should be equal ( $50 \%$ for each), this is again quite close to the equilibrium condition. For the set of all counteroffers with $X_{2}>$ $0.75 \mathrm{~W}$, the proportion that is cheap-talk signals and bluffs is even closer, $50.6 \%$ and $49.4 \%$, respectively.
} 
In fact, the relative rate of the two actions conform strikingly well to theory. Equation (5) in Section 2.2 provides the equilibrium condition that describes all theorized outcomes in the game (both with and without Honest Abes). The (conditional) rate of signaling, $1-\beta_{m}$, relative to the (conditional) rate of bluffing, $1-\beta_{n}$, should equal $\sigma /(1-\sigma)$; the relative probability of observing the two states of the world. Recall that in the experimental design the probability of common preference is $\sigma=0.8$. Hence, theory predicts that cheap-talk signaling should be more prevalent than bluffing and, specifically, it should be observed four times as frequently, [2]. Dropping the final round, due to the potential effects of play at the end of a finite game, bluffing occurs $21.6 \%$ of the time and cheap-talk signaling occurs at a rate of $72.0 \%$, which is over 3.3 times as great. Furthermore, the unconditional rates of cheap-talk signaling and bluffing should be equal. For all observations with either type of strategic information transmission attempted (those with $X_{2}>0.75 \mathrm{~W}$ ), the proportion that is cheap-talk signals and bluffs is quite close, $50.6 \%$ and $49.4 \%$, respectively. Therefore, bluffing and cheap-talk signaling behavior coincide with the theoretical model.

Figure 1 suggests that the subjects in the experimental sessions shifted equilibria. Initially, an equilibrium with low levels of information transmission are played. As bluffing is introduced into the group, the subjects gravitated toward play with both more bluffing and more cheap-talk signaling.

While Figure 1 illustrates that bluffing and cheap-talk signaling occur in the experimental sessions, Figure 2 investigates a contagion effect in the laboratory. For each session the first bluff that arises in that session (or bluffs if there is more than one in the round that bluffing first occurs) is identified. The average number of rejections per dyad, prior to the first bluff, can be compared to the average number of rejections in the rounds following the initial bluff round. The data for each session is centered around period 0 - the round with the first bluff - and behavior one and two periods prior (denoted -1 and -2 ) is compared with behavior one and two periods after (denoted +1 and +2 , respectively). 
Figure 2: Average Number of Rejections in a Dyad before and After the First Bluff

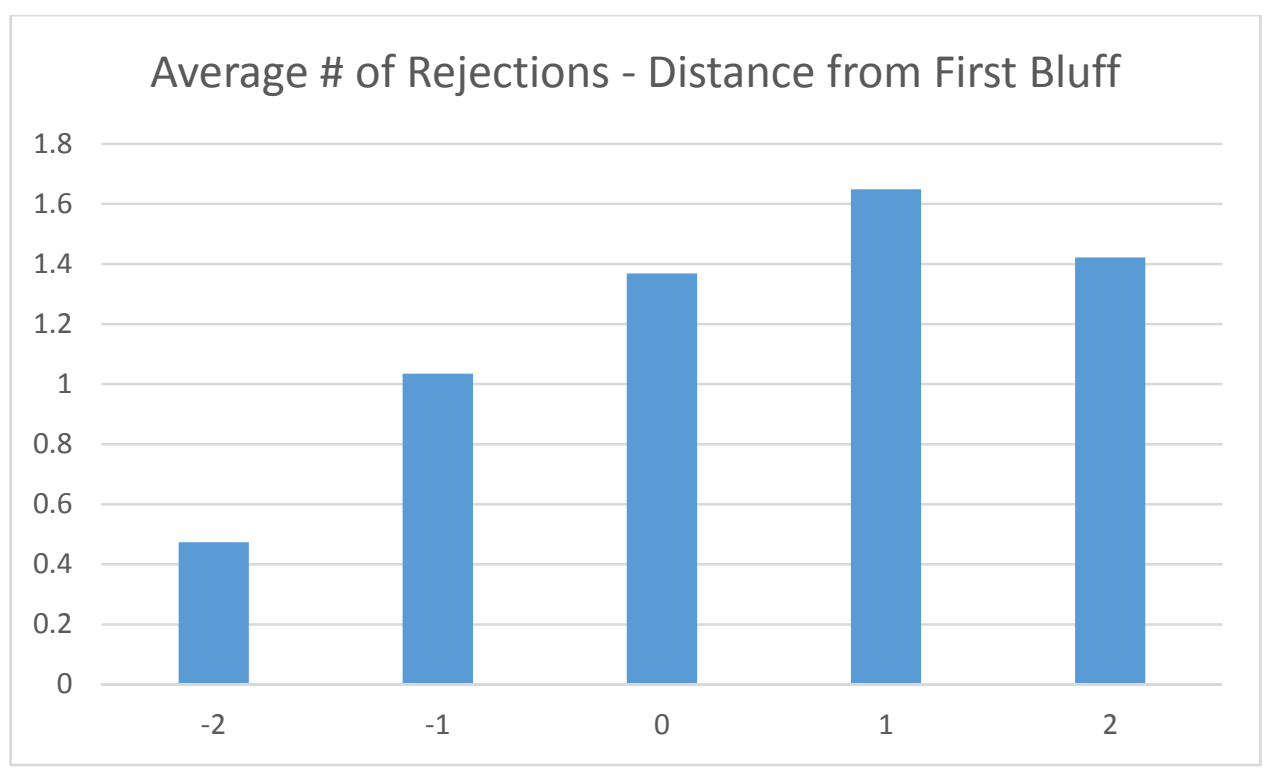

The figure illustrates the destructiveness of the first bluff in a group. Prior to the first bluff, the number of rejections observed is quite low. The average number of rejections over - 1 and -2 periods prior to the first bluff is less than 0.9 . The average number of rejections in the rounds +1 and +2 exceeds 1.5 . This is a $72 \%$ increase in the number of rejected offers. This suggests that bluffing creates a contagion that increases deadweight loss.

Table 4 presents a description of the results from the experiment. Along with full sample results of the outcomes in play, the sample is subdivided by the treatments considered and the (exogenous) state realized. 
TABLE 4: Results from the Experiment

\begin{tabular}{llllll}
\hline & $\begin{array}{l}\text { \# of } \\
\text { Rejections }\end{array}$ & $\begin{array}{l}\text { Rate of } \\
\text { Failure }\end{array}$ & $\begin{array}{l}\text { Agreed } \\
\text { Split }\end{array}$ & $\begin{array}{l}\text { Wealth } \\
\text { A }\end{array}$ & B \\
\hline Full Sample & 1.20 & $6.8 \%$ & $61.7 \%$ & $44.1 \%$ & $51.3 \%$ \\
Low Stakes & 0.98 & $4.8 \%$ & $62.0 \%$ & $43.3 \%$ & $50.3 \%$ \\
High Stakes & 1.42 & $8.9 \%$ & $61.4 \%$ & $44.9 \%$ & $52.2 \%$ \\
Low Costs & 1.16 & $6.2 \%$ & $60.1 \%$ & $42.4 \%$ & $52.8 \%$ \\
High Costs & 1.24 & $7.5 \%$ & $63.2 \%$ & $45.7 \%$ & $49.7 \%$ \\
Conflicting Preferences & 0.94 & $4.8 \%$ & $56.6 \%$ & $38.1 \%$ & $48.8 \%$ \\
Common Preferences & 1.93 & $12.5 \%$ & $75.7 \%$ & $60.6 \%$ & $58.1 \%$ \\
\hline
\end{tabular}

While the number of rejections exceeds one, on average, the standard deviation on the number of rejections per dyad is high (1.7). In fact, $49.9 \%$ of the pairings experienced no rejections, while almost $7 \%$ experienced full bargaining failure in that the maximum number of rejections arose. Consistent with Figure 1 (and the prediction [3] from the theoretical model), rejections were much more prevalent when the subjects had common preferences. Also, interestingly, rejections were much higher in the high stakes treatments. Again, this is consistent with the predictions from the theory, [5]. There is little difference, though, between the high cost and low cost treatments, [4]. The differences in rejected offers are mirrored when looking at whether the bargaining failed.

Regarding the agreed upon split of the endowment, Player B's in the experiment averaged a gain of over three-fifths of the pie. This was exaggerated when the parties had common preferences. Consistently across the treatments, Player As earned a lower percentage of the endowment in wealth than Player Bs. Presumably, this is due to the ability of the informed Player B to bluff. 


\section{Results}

To formally investigate the consequences of strategic information transmission the pooled data set can be considered. Section 4.1 examines the results of a regression analysis of bargaining decisions throughout the experiment. Additionally, the predictions of the theoretical model are tested and the contagion effect is explored. Section 4.2 searches for the Honest Abes in the sample and examines their impact on bluffs and welfare. The results from a modified experiment are presented in Section 4.3.

\subsection{Econometric Results}

To test the role of strategic communication on conflict, the number of rejections (Rejections $s_{i j}$ ) is used as the dependent variable. This is the important variable to appreciate as it captures the direct deadweight loss due to conflict and bargaining and that the comparative statics of the theoretical model predict that the treatments (and realized state) directly affect this number. Controls for the treatment (High Stakes $=1$ if and only if $W=120$ and High Cost $=1$ if and only if $C_{b}=10$ ) and session fixed effects are, therefore, included as explanatory variables. Also, measurements for the size of the opening offer $\left(\right.$ Open $_{i j}$ ) and the state of the world (Ace equals one if and only if the card randomly selected by Player $\mathrm{B}$ was an Ace) are incorporated. If bluffing and cheap-talk signaling cause additional conflict, then their measured marginal impact on the number of rejections should exceed one (since the act of bluffing and cheap-talk signaling requires that the opening offer is rejected). Table 5 presents the econometric results with standard errors clustered by round of play. 
TABLE 5: Results - Bluffing $(N=454)$

\begin{tabular}{|c|c|c|c|c|}
\hline dep. var. = & $\begin{array}{l}\text { Rejections } \\
\mathrm{I}\end{array}$ & II & $\begin{array}{l}\text { Offer } \\
\text { III }\end{array}$ & $\begin{array}{l}\text { Reject } \\
\mathrm{IV}\end{array}$ \\
\hline High Stakes & $\begin{array}{l}0.379 * * \\
(0.155)\end{array}$ & $\begin{array}{l}0.414 * * * \\
(0.134)\end{array}$ & $\begin{array}{l}0.005 \\
(0.014)\end{array}$ & $\begin{array}{l}0.444 * * \\
(0.216)[0.111]\end{array}$ \\
\hline High Costs & $\begin{array}{l}-0.211 * * * \\
(0.063)\end{array}$ & $\begin{array}{l}-0.193 * * * \\
(0.066)\end{array}$ & $\begin{array}{l}-0.003 \\
(0.009)\end{array}$ & $\begin{array}{l}-0.136 \\
(0.259)[-0.034]\end{array}$ \\
\hline Ace & $\begin{array}{l}0.285^{* *} \\
(0.138)\end{array}$ & $\begin{array}{l}1.618 * * * \\
(0.113)\end{array}$ & & $\begin{array}{l}2.068 * * * \\
(0.257)[0.451]\end{array}$ \\
\hline Offer & $\begin{array}{l}-2.055^{* * *} \\
(0.470)\end{array}$ & $\begin{array}{l}-2.462 * * * \\
(0.538)\end{array}$ & & $\begin{array}{l}-7.545 * * * \\
(1.731)[-1.886]\end{array}$ \\
\hline Bluff & $\begin{array}{l}2.388 * * * \\
(0.209)\end{array}$ & $\begin{array}{l}2.332 * * * \\
(0.189)\end{array}$ & & \\
\hline Signal & $\begin{array}{l}2.233 * * * \\
(0.286)\end{array}$ & & & \\
\hline Pre-Bluff & $\begin{array}{l}-0.146^{*} \\
(0.088)\end{array}$ & & $\begin{array}{l}-0.021 * * \\
(0.009)\end{array}$ & \\
\hline Signal x Post-Bluff & $\begin{array}{l}-0.377 \\
(0.484)\end{array}$ & & & \\
\hline Bluffed 1 & & $\begin{array}{l}0.181 * * * \\
(0.045)\end{array}$ & & $\begin{array}{l}0.571 * * \\
(0.243)[0.140]\end{array}$ \\
\hline Bluffed 2 & & & $\begin{array}{l}-0.039 * * * \\
(0.017)\end{array}$ & \\
\hline Bluffor 1 & & $\begin{array}{l}0.458 * \\
(0.256)\end{array}$ & $\begin{array}{l}-0.048 * * \\
(0.016)\end{array}$ & \\
\hline Bluffor 2 & & & & $\begin{array}{l}0.171 \\
(0.139)[0.043]\end{array}$ \\
\hline $\begin{array}{l}\text { Session Controls? } \\
\text { adj } R^{2}\end{array}$ & $\begin{array}{l}\text { YES } \\
0.485\end{array}$ & $\begin{array}{l}\text { YES } \\
0.411\end{array}$ & $\begin{array}{l}\text { YES } \\
0.070\end{array}$ & $\begin{array}{l}\text { YES } \\
0.220\end{array}$ \\
\hline AIC & 1482.3 & 1542.0 & -496.8 & 514.9 \\
\hline
\end{tabular}


Column I illustrates the breakdown in well-being when the trust in 'Honest Abes' succumbs to the bluffing of the 'Doc Hollidays'. Bluffing and cheap-talk signaling are both destructive activities. Attempting either generates more than two rejections. Given that each rejection reduces $8.3 \%$ to $25 \%$ of the surplus ${ }^{19}$, the destruction of attempted communication is substantial.

The rounds prior to the first bluff enjoy less conflict than rounds after. This is captured by the indicator variable Pre-Bluff, which is equal to one if and only if the observation occurred in a round prior to the first bluff arising in that session. The negative and statistically significant coefficient for Pre-Bluff suggests that bluffing spills over into the cooperativeness of the entire session. Given the mean value of Rejections from Table 4, being in a pre-bluff round decreases rejections by $13.9 \%$. The statisticallyinsignificant coefficient on the interaction term, Signal $x$ Post-Bluff, suggests that the effect of the introduction of bluffing does not impact the success of cheap-talk signaling.

As expected, the exogenous variation in the environment is correlated with bargaining conflict. Rejections are higher in high stakes situations than low stakes ones. Similarly, enhanced costs to conflict on behalf of the recipient of the initial offer is correlated with reduced rejections. Also, the size of the opening offer is correlated with conflict. More generous offers are, as one would expect, accepted. All of these effects were predictions of the theoretical model.

What the first column in Table 4 does not provide, though, is an explanation of the mechanism through which conflict permeates within a group. Multiple potential channels exist. One possibility is that bluffing is idiosyncratic. Once an individual adopts it as a tactic to extract more of the surplus in bargaining, overall conflict in future interactions will increase simply because that individual continues to employ the tactic. Rather, a Doc Holliday continues to bluff, which generates conflict. A second possibility is disease. An otherwise Honest Abe is exposed to the destructiveness of the addition of noise to the cheap-talk signals received. This infects the individual, turning them into a Doc Holliday who will bluff other individuals in future interactions.

The second column includes lagged effects. Bluffed 1 is an indicator variable equal to one if the subject was subjected to a bluff in the previous round. The variable Bluffor 1 is equal to one if the subject was the one who bluffed in the previous round. Both variables have positive and statistically significant coefficients. At the mean, an individual who experiences a bluff will experience a $15.6 \%$

\footnotetext{
${ }^{19}$ Since $C_{a}+C_{b}$ equal either 10 or 15 and the endowment is either 60 or 120 , each rejection destroys either $8.3 \%$, $12.5 \%, 16.7 \%$, or $25 \%$ of the surplus.
} 
increase in the number of rejections in the next interaction. Similarly, at the mean, an individual who bluffs in a round will experience $37.4 \%$ more rejections in the following negotiation.

The observation that both lagged variables are positive and statistically significant indicates that both hypotheses are occurring. Doc Hollidays continue to have conflict in future rounds, reducing welfare. They also infect others. Their partner is more likely to reject the opening offer in the next round.

The third column explores the cooperativeness of the individuals by considering their opening offer. An individual who bluffs in a round makes the opening offer in the next round. An individual who experiences a bluff in a round does not make another opening offer for two rounds. Thus, Bluffed 2 captures the effect of being the victim of a bluff the next time that person takes the role of Player $A$ in the game.

Both the coefficient on Bluffed 2 and Bluffor 1 are negative and statistically significant. The individual who bluffs in a round tends to make a less generous opening offer in the next round. At the mean value of Offer, the bluffor makes an offer that is $8.2 \%$ smaller. The individual who experiences the bluff makes an opening offer that is $9.7 \%$ smaller.

The negative and statistically significant coefficient on Pre-Bluff indicates another spillover effect of bluffing. In the interactions prior to the first bluff, opening offers are less. Once bluffing commences, the first-movers increase their opening offer, presumably in an attempt to reduce the level of destruction. Thus, there is a contagion effect.

Finally, the fifth column presents the results of a logit estimation with the binary variable Reject as the dependent variable. Logit coefficients are presented, while the standard errors clustered by round of play are given in the parentheses and the marginal effects are presented in the brackets.

The positive and statistically significant coefficient on Bluffed 1 indicates that those who are subject to a bluff are more likely to reject an offer in the next negotiation, even controlling for the presence of the Ace and the size of the opening offer. Again, this is evidence of the disease from playing with Doc Hollidays. The magnitude of the effect is substantial, increasing the likelihood of rejection by approximately 12 percentage points.

While the previous analysis focuses on impact of bluffing behavior. A complementary analysis can be done on the impact of cheap-talk signaling. As with bluffing, intertemporal variables can be created. The individual who received a cheap-talk signal, while in the role of Player A, takes a value of one for Signaled 1 in the next period and Signaled 2 in the period after that. The subject who made the 
cheap-talk signal, while in the role of Player B, takes values of one for Signalor 1 and Signalor 2 in the next two rounds. Table 6 presents the results.

TABLE 6: Additional Results - Signaling

$(N=454)$

\begin{tabular}{|c|c|c|c|c|}
\hline dep. var. = & Rejections & $\begin{array}{l}\text { Offer } \\
\text { II }\end{array}$ & $\begin{array}{l}\text { Reject } \\
\text { III }\end{array}$ & IV \\
\hline High Stakes & $\begin{array}{l}0.378 * * * \\
(0.141)\end{array}$ & $\begin{array}{l}0.006 \\
(0.014)\end{array}$ & $\begin{array}{l}0.482 * * \\
(0.220)[0.120]\end{array}$ & $\begin{array}{l}0.482 * * \\
(0.229)[0.120]\end{array}$ \\
\hline Asymmetric & $\begin{array}{l}-0.189 * * * \\
(0.061)\end{array}$ & $\begin{array}{l}-0.006 \\
(0.010)\end{array}$ & $\begin{array}{l}-0.114 \\
(0.250)[-0.029]\end{array}$ & $\begin{array}{l}-0.191 \\
(0.217)[-0.048]\end{array}$ \\
\hline Ace & $\begin{array}{l}0.253 * \\
(0.142)\end{array}$ & & $\begin{array}{l}2.073 * * * \\
(0.275)[0.452]\end{array}$ & $\begin{array}{l}2.103 * * * \\
(0.269)[0.457]\end{array}$ \\
\hline Offer & $\begin{array}{l}-2.008 * * * \\
(0.473)\end{array}$ & & $\begin{array}{l}-7.501 * * * \\
(1.822)[-1.875]\end{array}$ & $\begin{array}{l}-7.616 * * * \\
(1.810)[-1.904]\end{array}$ \\
\hline Bluff & $\begin{array}{l}2.430 * * * \\
(0.216)\end{array}$ & & & \\
\hline Signal & $\begin{array}{l}1.992 * * * \\
(0.208)\end{array}$ & & & \\
\hline Bluffed 1 & & & & $\begin{array}{l}0.593 * * \\
(0.261)[0.145]\end{array}$ \\
\hline Bluffor 2 & & & & $\begin{array}{l}0.199 \\
(0.125)[0.050]\end{array}$ \\
\hline Signaled 1 & $\begin{array}{l}0.002 \\
(0.196)\end{array}$ & & $\begin{array}{l}0.283 \\
(0.212)[0.070]\end{array}$ & $\begin{array}{l}0.376 * \\
(0.222) \text { [0.093] }\end{array}$ \\
\hline Signaled 2 & & $\begin{array}{l}0.028 \\
(0.027)\end{array}$ & & \\
\hline Signalor 1 & $\begin{array}{l}-0.098 \\
(0.142)\end{array}$ & $\begin{array}{l}0.009 \\
(0.027)\end{array}$ & & \\
\hline Signalor 2 & & & $\begin{array}{l}0.426 * * \\
(0.181)[0.105]\end{array}$ & $\begin{array}{l}0.370 * * \\
(0.188)[0.091]\end{array}$ \\
\hline
\end{tabular}




$\begin{array}{lllll}\text { Session Controls? } & \text { YES } & \text { YES } & \text { YES } & \text { YES } \\ \text { adj } R^{2} & 0.483 & 0.058 & 0.218 & 0.224 \\ \text { AIC } & 1483.6 & -492.1 & 515.9 & 516.2 \\ \% \text { correct } & & & 72.0 \% & 72.9 \%\end{array}$

Standard errors clustered by round of play.

*** $1 \%$; ** $5 \%$; * $10 \%$

The results in Table 6 reveal that cheap-talk signaling does not have the same degree of contagion effects as does bluffing. While the act of either signaling or bluffing increases the number of rejections, there is not a future effect on behavior. Those who signal in a round are not more or less likely to experience conflict while bargaining in the future. Similarly, those exposed to cheap-talk signals do not see changes in deadweight loss in future periods. The third and fourth columns present some evidence that the subjects who signal in a round are more likely to reject an offer in the future.

Rather than focus on conflict in bargaining, the contagion effect can be evaluated based on whether they encourage others to signal or bluff in future interactions. Table 7 presents results with the indicator variables Bluff and Signal as the dependent variables. 
TABLE 7: Explaining Information Transmission

(Subsample Comparisons)

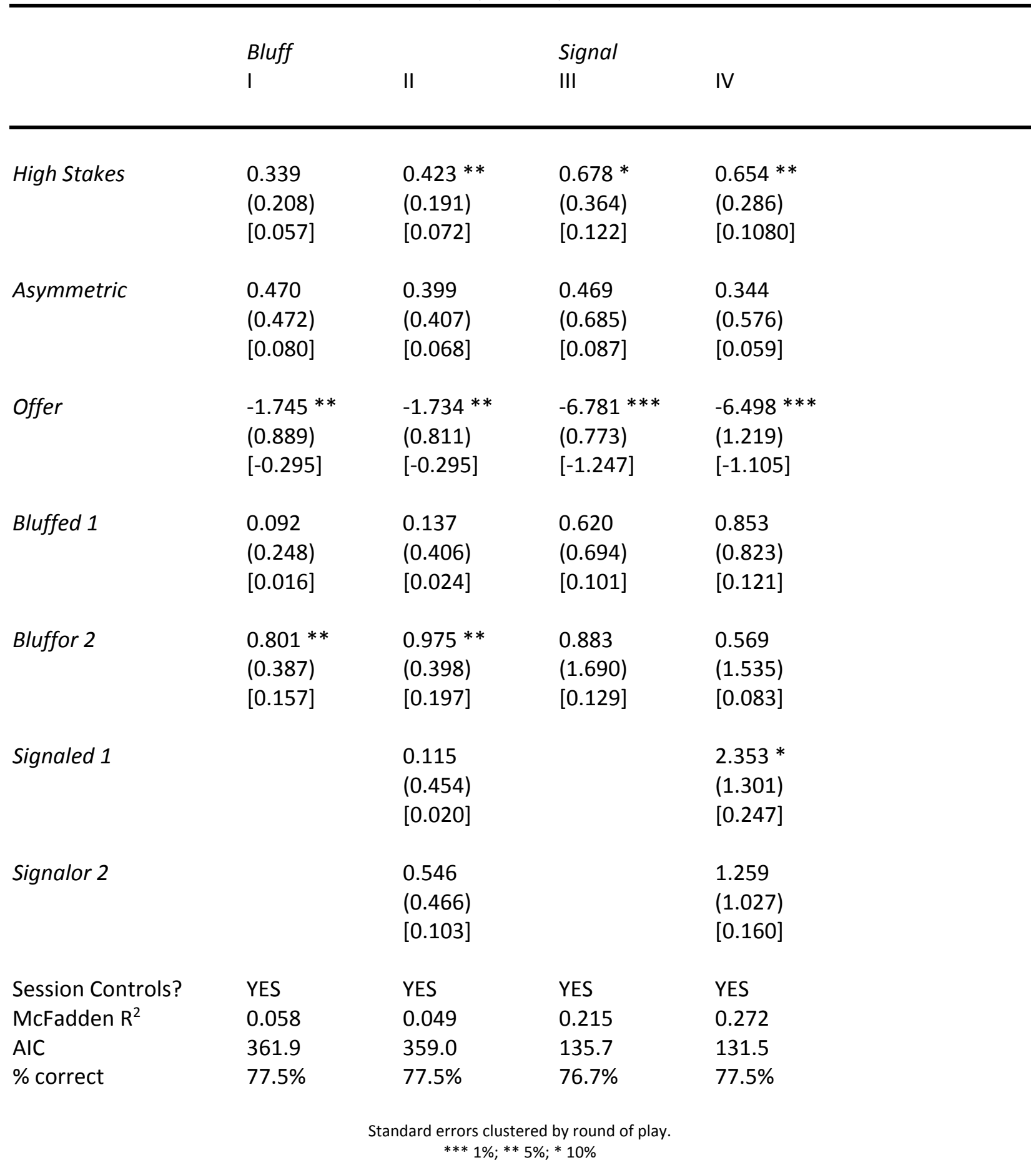

Thus, if one bluffs in a round, then two rounds later, when s/he has the option again, then bluffing is more likely to occur. We conclude that Doc Hollidays persist in their play, while Honest Abes remain 
honest. This effect does not seem to arise in the likelihood of cheap-talk signaling. Additionally, those who have signaled and those who have experienced a cheap-talk signal will increase the likelihood that they signal in future rounds. The former is a statistically significant effect.

\subsection{Searching for Honest Abe}

While the baseline model does not consider heterogeneity in the players, the Honest Abe extension does. Honest Abes differ in their utility function and, consequently, are theorized to engage in bluffing at a different rate. Hence, if the sample of subjects is differentiated based on their observed bluffing behavior, Honest Abes, if they exist, are less likely to engage in bluffing. Therefore, as a way to investigate heterogeneity in the population, the subject pool can be partitioned by bluffing behavior. The following table provides the subsample means for those who were the first to bluff in their session, those who never bluffed, and the rest of the sample who bluffed but only after others began bluffing. The assessments administered are used to differentiate subjects to identify whether or not there is heterogeneity in the subject population.

TABLE 8: Who is Honest Abe?

$\begin{array}{llllll} & \begin{array}{l}\text { \# Safe } \\ \text { Choices }\end{array} & \begin{array}{l}\text { E1 }-E 2 \\ \text { (ambiguity) }\end{array} & \begin{array}{l}\text { Dictator } \\ \text { (altruism) }\end{array} & \begin{array}{l}\text { \% } \\ \text { Males }\end{array} & \begin{array}{l}\text { Year in } \\ \text { School }\end{array} \\ \text { First Bluffers }(N=13) & 5.62 & -0.15 & 1.46 & 46.2 \% & 2.38 \\ \text { Bluffers }(N=43) & 5.87 & 1.19 & 1.80 & 64.3 \% & 2.55 \\ \text { Never Bluffed }(N=61) & 5.86 & 1.00 & 2.00 & 59.0 \% & 2.61\end{array}$

The subsample of those who engaged in the first bluff of their session ( $10.2 \%$ of the sample) look substantially different than the rest of the population. They are less risk averse, choosing fewer safe options in the Holt-Laury assessment. Additionally, they are registered as having less ambiguity aversion. In fact, the sample of first bluffers are, on average, ambiguity loving ( $E 1-E 2=0$ is ambiguity neutrality; $E 1-E 2>0$ is ambiguity aversion; $E 1-E 2<0$ is ambiguity love). Also, interestingly, the bluffers give 
substantially less in the Dictator Game. Finally, women are much more likely to be bluffers, as are younger students. Hence, this is suggestive evidence that play amongst heterogeneous actors is the appropriate framework to consider. ${ }^{20}$

\subsection{One-Shot Bargaining with Exogenous Offers}

The motivating, theoretical model employs a number of restrictive assumption to improve its tractability and provide testable hypothesis. Two assumptions are employed that differ from the experiment design. The first is that a one-shot bargaining environment is considered. The informed agent, first, has a one-time decision to bluff or cheap-talk signal and, similarly, the uninformed agent has a single choice to accept or reject the counteroffer. Second, the size of the initial offer and the counteroffer are exogenous so that the strategy set for each player is binary. The theoretical model, with these assumptions, provides the testable predictions outline in Section 2.4, but one could be concerned that an experimental design that has endogenous offers and a back-and-forth, alternatingoffers design may introduce confounding influences on behavior that are misattributed as a confirmation of the model.

Consequently, we conducted two additional sessions in February 2016 with a laboratory experiment that replicates the theoretical model. Subjects were recruited from across introductory and upper-level undergraduate courses at West Virginia University. A total of forty subjects participated (twenty in each session). From the background information collected, $28.9 \%$ are women (which is less than the previously studied subject pool), and $48.6 \%$ are business majors. In the risk assessment, the average value of Safe is 6.24 , and $53.7 \%$ of the subjects did not exhibit an Ellsberg-Paradox violation. Thus, the risk preferences are similar to that of the full sample (being slightly more risk averse) and preferences for ambiguity avoidance is prevalent, as in the full sample considered previously.

In the laboratory, the following game was played by the subjects. Subjects were informed that they would be randomly paired with a person in the other room and one would be randomly assigned to the role of "Player A", while the other is assigned to the role of "Player B". As in the main experiment, Player B drew a card from a deck containing only the Ten, Jack, Queen, King, and Ace. They were

\footnotetext{
${ }^{20}$ Given that the sample of first-bluffers is small, statistical tests are frustrated. Conducting a one-tailed differencein-means t-test, the gender distribution and ambiguity aversion differences are significant at the $10 \%$ level, while the risk aversion and Dictator differences are significant at the $20 \%$ level.
} 
informed that only Player B would learn the identity of the card. After the draw, there is an initial endowment of 60 "points" and the opening proposal is for each player to receive 30 . The informed Player B moves first deciding whether to accept or reject the offer. If the offer is accepted, then both players each receive 30 , regardless of which card B drew (and they were told that points converted to real dollars at the rate of 2 points $=\$ 1$ ). If Player B rejects the offer, then the endowment becomes 50 points. The uninformed Player A, then, decides whether to accept the offer of 50 or reject it. The players were informed that if $A$ rejects the 50 , then both receive only 10 points (again, regardless of the card drawn). Instead, if Player A accepts the offer, then Player B receives 50 regardless of the card. With A's acceptance, he receives 0 unless the card drawn at random was an Ace. In this situation, he too receives 50 points. The subjects were told that they would be making the decision problem only once and asked, prior to being randomly assigned to their roles, what they would like to do if selected to be Player A and if selected to be Player B, both with an Ace and without the Ace.

This experimental design is developed to replicate the theoretical model. Here the exogenous initial offer $\omega=30$ is fixed with the initial treatment of $\Omega=60$. This also closely matches the results of the main experiment as the average opening offer is $48 \%$ of the endowment. The endowment is reduced by 10 , again, matching the baseline treatment previously studied $\left(C_{a}=C_{b}=5\right)$. The counteroffer of $\Omega$, or rather, a counteroffer requesting all of the endowment (minus the costs of conflict) is exogenously set. Again, this not only replicates the theoretical model, but conforms to behavior in the alternating-offers experiment. In the data set, the average bluffing counteroffer is $95 \%$ of the endowment, with $92 \%$ of the subjects requesting $100 \%$ of it. The theoretical model is developed with the assumption that $Z$ is state independent, less than $\omega$, and greater than zero. Hence, $Z=10$ was employed. ${ }^{21}$ Thus, the design of the experiment replicates the theoretical model, and the parameters used match the typical outcomes of the baseline experiment.

The behavior in the one-shot bargaining environment with exogenous offers can be summarized. Table 8 presents the results.

\footnotetext{
${ }^{21}$ These parameter values are important also because a risk neutral, rational (Bayesian updating) subject has a simple decision problem. Without any updating, the unconditional probability of drawing an Ace, $1 / 5$, is such that the uninformed is indifferent between accepting and rejecting. If he accepts, then he earns 50 * Prob (Ace| reject), while if he rejects he earns 10 . Hence, if the updating increases the conditional probability of Player $B$ having the Ace (or rather, cheap-talk signaling is more likely than bluffing), then the offer should be accepted. Otherwise, it should be rejected.
} 
TABLE 9: One-Shot Bargaining with Exogenous Offers

$(N=40)$

Choice

Frequency

Player B: Accept the initial offer when holding the Ace

$32.5 \%$

Player B: Accept the initial offer when not holding the Ace

$80.0 \%$

Player A: Accept the counteroffer

$62.5 \%$

Player A's Assessments

Mean

St. Dev.

Probability $B$ rejects when holding the Ace

0.611

0.312

Probability $B$ rejects when not holding the Ace

0.472

0.303

Prob (reject| Ace) / Prob (reject| no Ace)

3.498

8.593

Consider, first, the top panel of Table 8. When in the role of the informed Player B, rejecting the initial offer of 30 is either a bluff, if the subject does not have the Ace, or is a cheap-talk signal when $s /$ he does have it. The first testable prediction is that both occur in equilibrium. This is confirmed in the experiment. In fact, $95 \%$ of the subjects engage in at least one of the two strategic communication behaviors. The second prediction is that the relative frequency of observing the two, conditional on the realized state, should be equal to four. Bluffing is chosen by $20 \%$ of the subjects and cheap-talk signaling is chosen by $67.5 \%$. Thus, the latter is selected 3.4 times as frequently. This closely replicates both the frequency in the baseline experiment (3.3) and the theoretical model.

The bottom panel explores behavior in more detail. Subjects were also asked, when in the role of Player A, what they believed the probability was that Player B would reject the initial offer, given the card s/he is holding; Prob (reject| Ace) and Prob (reject| no Ace). Again, subjects believe there are relatively high chances others will engage in strategic communication, and that cheap-talk signaling is more prevalent. Across the subjects, $67.5 \%$ believe cheap-talk signaling is more likely; Prob (reject| Ace) $\geq$ Prob (reject| no Ace).

With this additional information we can consider not only across-subject variation in decisions, but we can evaluate the within-subject consistency of decisionmaking. For each subject, the ratio of the 
probability of cheap-talk signaling over the probability of bluffing is calculated. The final row in Table 8 presents the descriptive statistics of this ratio. Interestingly, subjects on average believe cheap-talk signaling is 3.5 times as likely as bluffing. ${ }^{22}$ Thus, the predictions of the theoretical model are confirmed.

Finally, as in Section 4.2, the background controls and assessments can be compared of those who chose to bluff versus those who do not. As was the case in Table 9, women are much more likely to bluff ( $37.5 \%$ of bluffers versus $20.7 \%$ of non-bluffers), bluffers are less risk averse (5.88 versus 6.31 ), and less altruistic in the Dictator Game (1.88 versus 2.93). Thus, the findings in Table 9 persist in the new experimental method.

\section{Conclusion}

We explore theoretically and experimentally the possibility of bluffing and engaging in signaling when such communication is costless (i.e., cheap talk) in a bargaining environment with asymmetric information. Without separate messaging, any signaling would be expected to be babbling and, consequently ignored. This would lead one to expect that bluffing would be ineffective. We build a theoretical model, though, where bluffing and cheap-talk signaling occur with a positive probability in equilibrium. The equilibria can be Pareto-ranked and the equilibrium with no strategic information transmission is shown to be Pareto-inferior. An extension including the possibility of an Honest Abe in the game, who experiences a disutility from deceptive behavior, is considered. Ironically, the inclusion of Honest Abes increases deception in the game. An alternating-offers bargaining experiment is conducted with treatments varying the size of the costs to conflict and stakes of bargaining, as predicted to be drivers of behavior in comparative statics of the theory, are included. Along with establishing the prevalence of cheap-talk signaling and bargaining in the laboratory, we document a contagion effect. Experiencing a bluff causes a subject to create conflict in future interactions with different players. The contagion effect leads to overall more deadweight loss and encourages individuals to make more generous opening offers in an attempt, presumably, to reduce the destruction of bluffing. Cheap-talk signaling efforts are not reduced by the increase in bluffing, but rather the two co-move.

${ }^{22}$ Observations where subjects place zero probability of bluffing are omitted since it is in the denominator. 
Additionally, further investigation into the functioning of the contagion effect is needed. One can hypothesize that exposure to bluffing adjusts an agent's empirical social norm expectations. This has been shown to predict, for example, altruistic giving in the Dictator Game

The results suggest that more attention needs to be paid to the role of costless communication of asymmetric information and, specifically, deception in economic environments. Individuals attempt to convey information through their actions even when standard, costly signaling (a la Spence (1973)) is not possible. These behaviors are not irrational, but rather can exist in equilibrium and can be escalated when individuals experience disutility from acting deceptively. Regulatory and legal institution design, for example, should consider how the established mechanisms facilitate or dissuade cheap-talking and bluffing as their use has welfare consequences.

\section{References}

Austen-Smith, David, and Jeffrey S. Banks (2000), Cheap Talk and Burned Money, Journal of Economic Theory 134(1): 93-116.

Bibas, Stephanos (2011), Regulating the Plea-Bargaining Market: From Caveat Emptor to Consumer Protection, California Law Review 99(4): 1117-1161.

Bicchieri, Cristina, and Erte Xiao (2008), Do the Right Thing: But Only If Others Do So, Behavioral Decision Making 22(2): 191-208.

Boles, Terry L., Rachel T. A. Croson, and J. Keith Murnigham (2000), Deception and Retribution in Repeated Ultimatum Bargaining, Organizational Behavior and Human Decision Processes 83(2): 235-259.

Brandenburger, Adam M., and Barry J. Nalebuff (1997), Co-Opetition, New York: Doubleday. 
Brandts, Jori, and Gary Charness (2003), Truth or Consequence: An Experiment, Management Science 49(1): 116-130.

Callander, Steven, and Simon Wilkie (2007), Lies, Damned Lies, and Political Campaigns, Games and Economic Behavior 60(2): 262-286.

Charness, Gary, and Martin Dufwenberg (2006), Promises and Partnerships, Econometrica 50: 15791601.

Chen, Jingnan, and Daniel Houser (2013), Promises and Lies: An Experiment on Detecting Deception, Interdisciplinary Center for Economic Science Discussion Paper.

Crawford, Vincent P. (2003), Lying for Strategic Advantage: Rational and Boundedly Rational Misrepresentation of Intentions, American Economic Review 93(1): 133-149.

Crawford, Vincent P., and Joel Sobel (1982), Strategic Information Transmission, Econometrica 50(6): 1431-1451.

Croson, Rachel, Terry Boles, and J. Keith Murnigham (2003), Cheap Talk in Bargaining Experiments: Lying and Threats in Ultimatum Games, Journal of Economic Behavior \& Organization 51(2): 143-159.

De Haan, Thomas, Theo Offerman, and Randolph Sloof (2015), Money Talks? An Experimental Investigation of Cheap Talk and Burned Money, International Economic Review 56(4): 1385-1426.

Deck, Cary, Jungmin Lee, Javier Reyes, and Chris Rosen (2012), Risk-Taking Behavior: An Experimental Analysis of Individuals and Dyads, Southern Economic Journal 79(2): 277-299. 
Detotto, Claudio, and Bryan C. McCannon (2016), Consolidation of Prosecutor Offices, Working Paper.

Duffy, John, and Nick Feltovich (2006), Words, Deeds, and Lies: Strategic Behavior in Games with Multiple Signals, Review of Economic Studies 73: 669-688.

Ellsberg, Daniel (1961), Risk, Ambiguity and the Savage Axioms, Quarterly Journal of Economics 75(4): 643-669.

Farmer, Amy, and Paul Pecorino (2013), Discovery and Disclosure with Asymmetric Information and Endogenous Expenditures at Trial, Journal of Legal Studies 42(1):" 223-247.

Gneezy, Uri (2005), Deception: The Role of Consequences, American Economic Review 95(1): 384-394.

Halevy, Yoram (2007), Ellsberg Revisited: An Experimental Study, Econometrica 75(2): 503-536.

Hurkens, Sjaak, and Navin Kartik (2009), Would I Lie to You? On Social Preferences and Lying Aversion, Experimental Economics 12: 180-192.

Hòlm, Hakan J. (2004), Biases in Bluffing - Theory and Experiments, Lund University Working Paper Series

Hölm, Hakan J. (2010), Truth and Lie Detection in Bluffing, Journal of Economic Behavior \& Organization 76: 318-324.

Holt, Charles A., and Susan K. Laury (2002), Risk Aversion and Incentive Effects, American Economic Review 92(5): 1644-1655.

Kartik, Navin (2007), A Note on Cheap Talk and Burned Money, Journal of Economic Theory 136(1): 749758. 
Kartik, Navin (2009), Strategic Communication with Lying Costs, Review of Economic Studies 76(4): 13591395.

Kartik, Navin, and R. Preston McAfee (2007), Signaling Characteristics in Electoral Competition, American Economic Review 97(3): 852-870.

Kartik, Navin, Marco Ottaviani, and Francesco Squintani (2007), Credulity, Lies, and Costly Talk, Journal of Economic Theory 134(1): 93-116.

Kawagoe, Toshiji, and Hirokazu Takizawa (2009), Equilibrium Refinement vs. Level-k Analysis: An Experimental Study of Cheap-Talk Games with Private Information, Games and Economic Behavior 66(1): 235-268.

Loch, Christoph H., and Yaozhong Wu (2008), Social Preferences and Supply Chain Performance: An Experimental Study, Management Science 54(11): 1835-1849.

Leaver, Clare (2009), Bureaucratic Minimal Squawk Behavior: Theory and Evidence from Regulatory Agencies, American Economic Review 99(3): 572-607.

Levitt, Steven D. and Chad Syverson (2008), Market Distortions When Agents Are Better Informed: The Value of Information in Real Estate Transactions, Review of Economics and Statistics 90(4): 599-611.

McCannon, Bryan C. (2011), The Distortion of Criminal Evidence, Journal of Economic Policy Reform 14(1): 59-67.

McCannon, Bryan C. and John B. Stevens (2015), The Role of Personality Style in Bargaining, Working Paper. 
McCannon, Bryan C., Colleen Tokar Asaad, and Mark Wilson (2015), Financial Competence, Overconfidence, and Trusting Investments: Results from an Experiment, Journal of Economics and Finance (forthcoming)

Miettinen, Topi (2013), Promises and Conventions - An Approach to Pre-Play Agreements, Games and Economic Behavior 80(1): 68-84.

Rubinstein, Ariel (1982), Perfect Equilibria in a Bargaining Model, Econometrica 50(1): 97-109.

Sánchez-Pagés, Santiago, and Marc Vorsatz (2007), An Experimental Test of Truth-Telling in a SenderReceiver Game, Games and Economic Behavior 61(1): 86-112.

Serra-Garcia, Marta, Eric van Damme, and Jan Potters (2013), Lying About What You Know Or About What You Do, Journal of the European Economic Association 11(5): 1204-1229.

Spence, Michael F. (1973), Job Market Signaling, Quarterly Journal of Economics 87(3): 355-374.

Sterbenz, Frederic P., and Owen R. Phillips (2001), Bargaining Experiments with Deadlines and Random Delays, Economic Inquiry 39(4): 616-626.

Vanberg, Christoph (2008), Why Do People Keep Their Promises? An Experimental Test of Two Explanations, Econometrica 76(6): 1467-1480.

Wang, Joseph Tao-Yi, Michael Spezio, and Colin F. Camerer (2010), Pinocchio's Pupil: Using Eyetracking and Pupil Dilation to Understand Truth-Telling and Deception in Games, American Economic Review 100: 984-1007.

Zwick, Rami and Xiao-Ping Chen (1999) What Price Fairness? A Bargaining Study, Management Science 45(6): 804-823.

\section{Appendix}


The script used in the experimental sessions is provided.

Welcome to the research session in economics. We greatly appreciate your willingness to participate and help us with our project. We first want to provide some information before we start playing the games.

We are going to be playing a game and completing a survey. The game, though, will be repeated and divided into four different versions of the game. Each version of the game will be played four times. Soon we will be explaining the rules of the game. The survey will be given after the game.

We expect this session to last approximately one hour. You will be paid for participating. How much you earn will depend on the choices you make, the choices made by other players in the game, and luck. We expect on average people will make $\$ 20$, but we guarantee that no one will make less than $\$ 10$. You could earn more as well.

First, though, we need to go over the consent form.

[Go over the consent form and collect signatures before continuing]

Thank you. Now let's turn to the game.

In each round of each version of the game you will earning "points." These points will be cashed in for actual dollars. At the end of our session tonight, one round of the game will be selected at random. The number of points you earn in that round will be converted into real dollars at the exchange rate of 2 points $=\$ 1$.

In the first version of the game you will be paired with someone in the next room to play a twoperson game. One of you will be assigned the label of "Player A" while the other will take the label of "Player B." We will play this version of the game four times so that twice you will be Player A in the game and twice you will be Player B. In every round of the game you will be paired with someone different in the other room. The pairings will be made at random. At no time will you know the name of the person you are paired with nor will they know your identity.

The slides on the overhead screen will explain the rules of the game.

\section{[Go through the slide presentation.]}

[Provide an opportunity for subjects to ask questions.]

\section{[Play the game]}

That concludes the first of two activities. Now, we turn to the survey. In the packet of paperwork given to you there are a number of assessments. The first asks you basic background information. Using a pencil, respond to these on the scantron sheet provided.

After you have completed that, there are three additional assessments. The first one asks you to make a choice between either option (a) in the first column or option (b) in the second column. For each of the numbered choices 6-15 you are to select either (a) or (b).

For each option you are going to receive one of the two numbers. For option (a) you will receive either 10 or 8 points. For option (b) you are going to receive either 19.25 or 0.5 points. To play each lottery, a number between one and ten will be selected at random. If you choose option (a), for example, you will receive 10 points if one of the numbers associated with it are drawn and 8 points if the other numbers are drawn.

[Select one as an illustration - use the slides.]

Regarding compensation, one of the questions on the survey will be selected at random. The lottery will be played and you will receive real money based on how much you receive.

Complete the survey by filling in the option you wish to select on the scantron for each of the 10 decision problems.

The second assessment is another lottery. Here either the number 1 or 2 will be drawn. You will receive the associated outcome. Again, you are to select either option (a) or option (b). Make your selection in pencil on the scantron sheet provided. 
The difference with this assessment is that for some choices you will see two numbers in brackets. This means that another selection of either the number 1 or 2 . If 1 is selected, then the first number in the bracket is realized, while if 2 is selected the second one is chosen.

[Select one as an illustration - use the slides.]

Again, one of the lottery choices on these two assessments will be selected and the outcome you receive will be converted into real dollars. If an outcome on the second assessment is chosen, the points are converted into dollars at the exchange rate of 10 points $=\$ 1$

[Ask for questions and answer. Make sure people understand the assessments.]

Finally, the third assessment asks to you answer a series of questions. Provide your answers on the scantron. When you are done with all three assessments bring your results to the front podium and receive your money. Thank you again!

Here is the decision problem given to the subjects in the final two sessions.

You are going to be randomly paired with another individual in the room.

One of you will (randomly) assigned the role of "Player A", while the other is "Player B".

Player B randomly draws a card from a deck that contains only five cards: Ten, Jack, Queen, King, Ace.

Player A does not see which card was drawn.

After seeing his/her card, Player B makes the decision to either ACCEPT an offer of $\mathbf{3 0}$ or REJECT.

If the offer of 30 is accepted, Player $B$ receives 30 points (regardless of which card s/he drew)

$\ldots$ and, Player A receives 30 points (again, regardless of which card Player B drew).

If the offer of $\mathbf{3 0}$ is rejected (by B), then Player A has the decision to ACCEPT an offer of 50 or REJECT. ... still not knowing which card Player $B$ drew

If the offer of 50 is accepted by Player A, then Player B receives 50 points (regardless of the card), and ... either Player A receives 50 points - if the card is an Ace

... or Player A receives 0 points - if the card is a Ten, Jack, Queen, or King.

If the offer of 50 is rejected by Player A, then both Player A and Player B receive 10 points.

\section{Answer the following questions by writing the word "accept" or "reject" on the line for each:}

[1] If you are the one randomly selected to take the role of Player B, would you ACCEPT or REJECT the initial offer of 30

... when you drew the Ace

... when you drew a Ten, Jack, Queen, or King

[2] If you are the one randomly selected to take the role of Player A (and Player B has chosen to reject the initial offer), would you ACCEPT or REJECT the 50?

Accept or reject? 
What do you think is the probability Player $B$, when he or she has the Ace, will reject the offer of 30 ? (Write a probability between 0 and 1 )

What do you think is the probability Player $B$, when he or she does not have the Ace, will reject the offer of 30 (Write a probability between 0 and 1 )

Finally, Section 4.3 discusses the difference between the bluffers and non-bluffers in the extended experimental sessions. Table A1 presents the subsample comparisons.

TABLE A1: Who is Honest Abe?

\begin{tabular}{llllll}
\hline & $\begin{array}{l}\text { \# Safe } \\
\text { Choices }\end{array}$ & $\begin{array}{l}\text { Ellsberg } \\
\text { Consistent }\end{array}$ & $\begin{array}{l}\text { Dictator } \\
\text { (altruism) }\end{array}$ & $\begin{array}{l}\text { \% } \\
\text { Males }\end{array}$ & $\begin{array}{l}\text { Year in } \\
\text { School }\end{array}$ \\
\hline Bluffers & 5.88 & $37.5 \%$ & 1.88 & $37.5 \%$ & 1.13 \\
Non-Bluffers & 6.31 & $55.2 \%$ & 2.93 & $20.7 \%$ & 1.66
\end{tabular}

As in Table 9 in the text, individuals willing to bluff are less risk averse than those who do not bluff. Similarly, bluffers are less altruistic, younger, and more likely to be women. Finally, for the extended sessions, an assessment of preferences that are consistent across lotteries with and without ambiguity are conducted. Bluffers are less likely to have consistent decisions, which is in line with the results in Table 8 where first-bluffers are more likely to be ambiguity averse. 